\title{
Epidendrum L. (Orchidaceae, Epidendroideae) no Parque Nacional da Chapada dos Veadeiros, Estado de Goiás, Brasil
}

\author{
Igor Soares dos Santos ${ }^{1,2}$ \& (D) Marcos José da Silva ${ }^{1}$
}

Recebido: 20.03.2020; aceito: 05.08.2020

Como citar: Santos, I.S. \& Silva, M.J. 2020. Epidendrum L. (Orchidaceae, Epidendroideae) no Parque Nacional da Chapada dos Veadeiros, Estado de Goiás, Brasil. Hoehnea 47: e202020. http://dx.doi.org/10.1590/2236-8906-20/2020.

RESUMO - (Epidendrum L. (Orchidaceae, Epidendroideae) no Parque Nacional da Chapada dos Veadeiros, Estado de Goiás, Brasil). Epidendrum L. é um dos maiores gêneros de Orchidaceae Juss. com 2.400 espécies neotropicais, 121 das quais presentes no Brasil, sendo 69 delas endêmicas. A taxonomia das espécies de Epidendrum na região Centro-Oeste é escassamente conhecida e vinculada a estudos florísticos sobre Orchidaceae. É apresentado o tratamento taxonômico às espécies de Epidendrum ocorrentes no Parque Nacional da Chapada dos Veadeiros, uma das Áreas de Preservação Permanentes mais importantes do Brasil. Foram encontradas seis espécies: E. avicula Lindl., E. campacci Hágsater \& L. Sánchez, E. dendrobioides Thunb., E. nocturnum Jacq., E. rothii A.D. Hawkes e E. secundum Jacq., crescendo como epífitas, terrícolas e rupícolas em distintas fitofisionomias. As espécies seguem descritas e ilustradas, comentadas quanto a distribuição geográfica, relações morfológicas, fenologia, bem como contrastadas por meio de uma chave dicotômica e alocadas em grupos informais reconhecidos para o gênero.

Palavras-chave: Cerrado, diversidade, flora, orquídeas, Taxonomia

ABSTRACT - (Epidendrum L. (Orchidaceae, Epidendroideae) in the Parque Nacional da Chapada dos Veadeiros, Goiás State, Brazil). Epidendrum L. is one of the largest genera of Orchidaceae Juss. with 2.400 neotropical species, 121 of which are present in Brazil, 69 of which are endemic. The taxonomy of Epidendrum species in the Central-West region is scarcely known and linked to floristic studies on Orchidaceae. Taxonomic treatment of Epidendrum species in the Parque Nacional da Chapada dos Veadeiros, one of the most important Permanent Preservation Areas in Brazil, is presented. Six species were found: E. avicula Lindl., E. campacci Hágsater \& L. Sánchez, E. dendrobioides Thunb., E. nocturnum Jacq., E. rothii A.D. Hawkes and E. secundum Jacq., growing as epiphytes, terrestrial and rupicolous in different phytophysiognomies. The species are described and illustrated, commented on geographic distribution, morphological relationships, phenology, as well as contrasted in a dichotomous key and allocated to informal groups recognized for the genus.

Keywords: Cerrado, diversity, flora, orchids, Taxonomy

\section{Introdução}

Epidendrum L. pertence à subfamília Epidendroideae Lindl., tribo Epidendreae Kunth, subtribo Laeliinae Benth., e é um dos maiores e mais complexos gêneros da família Orchidaceae Juss. (Chase et al. 2015), com aproximadamente 2.400 espécies dispersas pela região Neotropical (Hágsater et al. 2016). No Brasil representa-se com por 121 espécies, das quais 69 são endêmicas, distribuídas de norte a sul, sobretudo, pelas florestas úmidas do norte ao leste do país e também nas formações savânicas de sua porção central (BFG 2018, Flora do Brasil 2020, em construção).

Diversas classificações infragenéricas têm sido propostas para Epidendrum (e.g., Lindley 1852-1859, Cogniaux 18981902, Pabst \& Dungs 1975, Brieger 1976-1977, Hágsater 1985), baseadas em caracteres morfológicos. Todavia,

1. Universidade Federal de Goiás, Instituto de Ciências Biológicas, Laboratório de Morfologia e Taxonomia Vegetal, Departamento de Botânica, Alameda Ingá, Quadra A, Campus Samambaia, 74001-970 Goiânia, GO, Brasil

2. Autor para correspondência: igorsoares1237@gmail.com 
nenhuma delas reflete as hipóteses filogenéticas atuais para o gênero (e.g., Hágsater \& Soto-Arenas 2005, Klein et al. 2019, Mendoza et al. 2020). Na década de setenta, o mesmo foi subdividido em quatro subgêneros: Amphiglottium Lindl., Euepidendrum Lindl., Spathium Lindl. e Strobilifera Lindl. (Brieger 1976-1977). Atualmente, são reconhecidos mais de 80 grupos informais para o gênero, diferenciados, sobretudo, por sua morfologia floral e aspectos vegetativos. Apesar disso, tais grupos são complexos e difíceis de se interpretar, pois Epidendrum é um gênero morfologicamente diverso e possui um expressivo número de nototáxons (ca. 30), complexos específicos e espécies crípticas (FernándezConcha \& Ramírez-Morillo 2003, Hágsater \& Soto-Arenas 2005, Hágsater \& Saldaña 2006, Assis et al. 2013, Moraes et al. 2013, Pinheiro \& Cozzolino 2013, Marques et al. 2014), o que torna a sua taxonomia complexa.

Espécies de Epidendrum são reconhecidas pelos caules longos cilíndricos ou compressos, intumescidos ou não em pseudobulbos, folhas dísticas, inflorescência terminal, flores com o labelo adnato à coluna, rostelo fendido paralelo ao eixo da coluna, cavidade estigmática ampla, nectário do tipo cunículo e anteras com (2) 4 (6-8) polínias ceroides, achatadas lateralmente, mono ou heteromórficas (Hágsater \& Soto-Arenas 2005, Stancik et al. 2009).

No Estado de Goiás, estudos referentes à taxonomia de Epidendrum inexistem, a exceção do trabalho de Hall et al. (2013) tratando das Orchidaceae no município de Caldas Novas, referiram seis espécies para o gênero. Além desse trabalho, Pessoa (2020) tem citado 33 e 21 espécies, para o gênero na região Centro-Oeste e no Estado de Goiás no site Lista das espécies da Flora do Brasil (http://floradobrasil.jbrj.gov.br/reflora/floradobrasil/ FB11518), respectivamente. Espécies do gênero são ainda citadas em estudos fitossociológicos e florísticos pontuais, como àqueles elaborados para o Parque Estadual dos Pireneus (Bosquetti 2008), Chapada dos Veadeiros (Mendonça et al. 2007) e Alto Paraíso de Goiás (Munhoz \& Proença 1998, Munhoz \& Felfili 2006, Eugênio et al. 2011, Chaves 2012). Ressalta-se que, em alguns estudos, assim como em coleções de herbários, espécies do gênero são equivocadamente identificadas e/ou correspondem a binônimos desatualizados, revelando a necessidade de estudos mais atuais para o gênero.

Objetivou-se o tratamento taxonômico às espécies de Epidendrum ocorrentes no Parque Nacional da Chapada dos Veadeiros, Goiás, Brasil.

\section{Material e métodos}

O Parque Nacional da Chapada dos Veadeiros (PNCV), criado pelo Decreto 49.875 em 1961, é uma das Áreas de Preservação Permanente (APPs) mais importantes do Brasil, sendo declarado Sítio do Patrimônio Natural Mundial pela
Organização das Nações Unidas para a Educação, Ciência e Cultura (UNESCO 2001), por reunir uma grande diversidade biológica, e se tratando de plantas, são registradas cerca de 1.640 espécies, muitas das quais são raras e endêmicas, o que o torna uma das áreas prioritárias para conservação da biodiversidade (Mantovani \& Pereira 1999, MMA 2005, ICMBio 2009).

O PNCV compreende uma área de 65.510 ha localizada no nordeste do Estado de Goiás (Fig.1a), abrangendo os municípios de Alto Paraíso de Goiás, Cavalcante, Teresina de Goiás (ao norte) e Colinas do Sul (a oeste), cuja vegetação nativa é majoritariamente relictual do Domínio Fitogeográfico Cerrado, entre $13^{\circ} 50^{\prime}-14^{\circ} 12^{\prime} \mathrm{S}$ e $47^{\circ} 24^{\prime}-47^{\circ} 58^{\prime} \mathrm{W}$ (Dardenne \& Campos 2002, Ferreira et al. 2006, Fiedler et al. 2006). Sua superfície abrange um complexo montanhoso com distintos tipos de solos e relevos, além de uma vegetação heterogênea (Fig. 1b-i) exemplificada por distintas fisionomias (e.g., campo limpo, sujo ou rupestre, cerrados densos, ralos, rupestres e típicos, matas ciliares, secas ou de galeria, florestas estacionais e veredas). Apresenta altitudes de 800 até 1.676 metros, e clima, segundo a classificação de Köepen, Tropical Semiúmido (Aw), caracterizado por invernos frios e secos e verões quentes e chuvosos, com precipitação média anual entre 1.500 e $1.750 \mathrm{~mm}$, e temperaturas entre $24-26{ }^{\circ} \mathrm{C}$ (Felfili et al. 2007).

A coleta do material botânico foi realizada entre os meses de julho 2017 e outubro de 2018 segundo as recomendações de Mori et al. (1989), onde informações referentes a coloração das peças florais, fenologia, habitats, e preferências ambientais, assim como o georreferenciamento, foram anotadas em caderneta de campo para todas as espécies. As espécies foram fotografadas em seus hábitats e suas flores e frutos foram preservados em álcool etílico $70 \%$ para auxiliar no estudo morfológico comparativo, na identificação e na elaboração das respetivas ilustrações. O material coletado foi incorporado ao acervo do Herbário da Universidade Federal de Goiás (UFG).

As espécies foram identificadas a partir dos trabalhos de Hágsater \& Salazar (1993), Stancik et al. 2009, Hágsater \& Sánchez (2010), Hall et al. (2013), Lima (2014) e por meio da análise de coleções provenientes de 20 herbários: CEN, CEPEC, CVRD, ESA, FURB, HEPH, HUEFS, HUFU, IAN, IBGE, INPA, K, MAC, NY, P, RB, SJRP, UB, UEC e UFG, incluindo coleções tipo (acrônimos segundo Thiers 2020). As terminologias adotadas fundamentaram-se na literatura especializada supracitada, enquanto que as ilustrações das espécies foram confeccionadas pelo primeiro autor do manuscrito, por meio de um estereomicroscópio Zeiss, com câmara clara acoplada, e contemplam caracteres diagnósticos ao reconhecimento dos táxons. O mapa da área de estudo (PNCV) foi elaborado no software QGIS (Quantum GIS Development Team) version 2.8.1. 

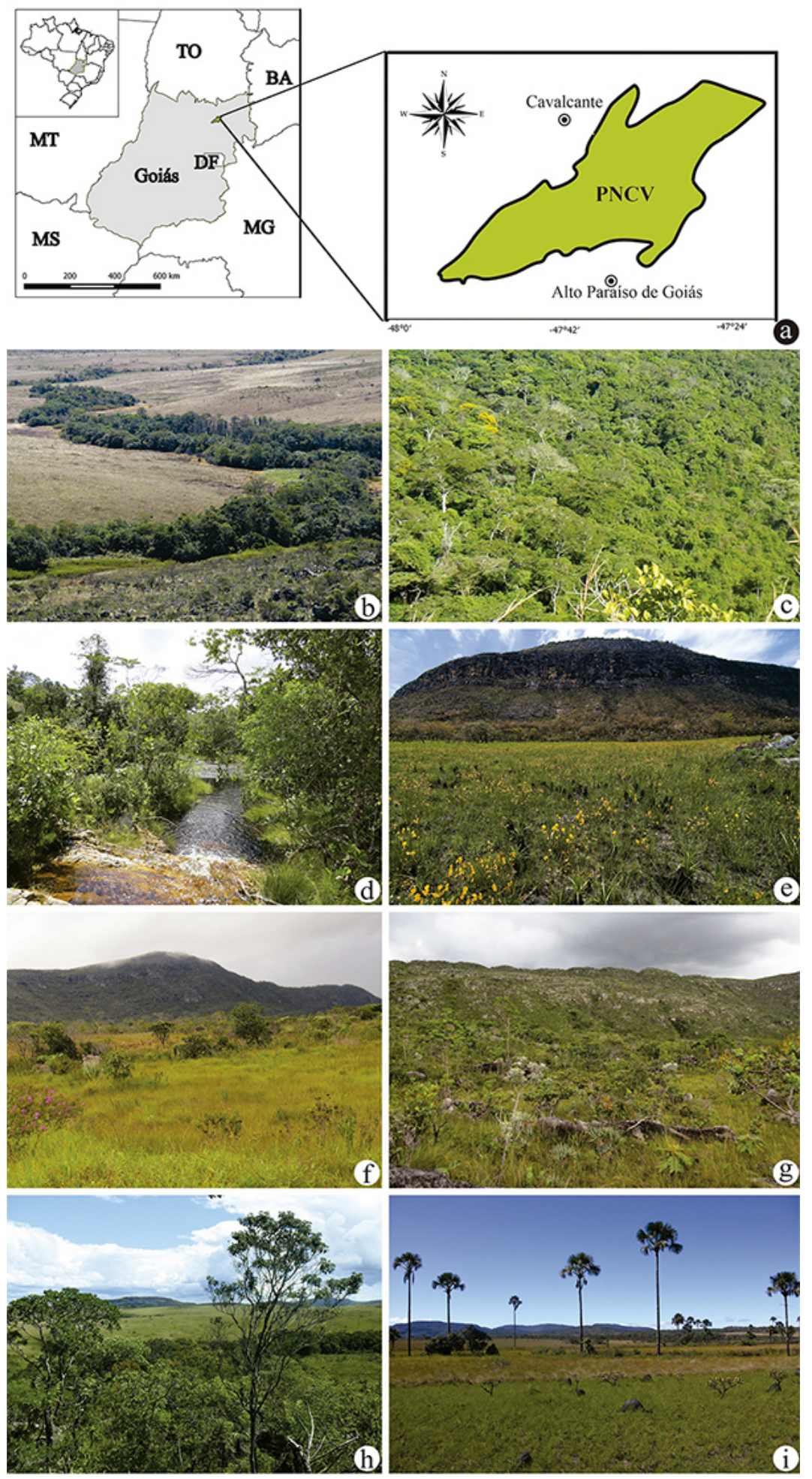

Figura 1. Parque Nacional da Chapada dos Veadeiros (PNCV) e fitofisionomias. a. Mapa do Brasil destacando o Estado de Goiás e o PNCV. Fitofisionomias - b-c. Mata de galeria. d. Mata ciliar. e. Campo limpo pós fogo. f. Campo sujo. g. Campo rupestre. h. Cerrado rupestre. i. Vereda. Onde: BA: Estado da Bahia. DF: Distrito Federal. MG: Estado de Minas Gerais. MT: Estado de Mato Grosso. MS: Estado de Mato Grosso do Sul. TO: Estado do Tocantins.

Figure 1. Parque Nacional da Chapada dos Veadeiros (PNCV), and phytophysiognomies. a. Map of Brazil highlighting the State of Goiás and the PNCV. Phytophysiognomies - b-c. Gallery forest. d. Ciliar forest. e. Clean field after fire. f. Dirty field. g. Rupestrian field. $h$. Rock field. i. Vereda. BA: Bahia State. DF: Distrito Federal. MG: Minas Gerais State. MT: Mato Grosso State. MS: Mato Grosso do Sul State. TO: Tocantins State. 


\section{Resultados e Discussão}

Epidendrum L., Sp. Pl. ed. 2, p.1347. 1763.

Ervas rupícolas, epífitas e terrícolas, eretas ou pendentes com rizomas longos ou encurtados; cauloma intumescido ou não em pseudobulbo, simples ou ramificado, compresso ou cilíndrico com folhas dísticas coriáceas, subcoriáceas, cartáceas, submembranáceas ou membranáceas, planas, conduplicadas ou côncavas; racemos, corimbos ou panículas eretas ou pendentes, basalmente envolvidas ou não por brácteas cartáceas, coriáceas e membranáceas, imbricadas ou não; flores ressupinadas ou não, com labelo inteiro, 3-lobado ou 3-partido, raramente 4-lobado, adnato à coluna, usualmente plano ou conduplicado, caloso ou não; rostelo fendido paralelo ao eixo da coluna; anteras com duas, quatro, seis ou oito (geralmente quatro) polínias mono ou heteromórficas, amarelas, ceroides e achatadas lateralmente; viscídio semi-líquido; cavidade estigmática ampla; ovário com ou sem nectário do tipo cunículo, antera incumbente, terminal ou dorsal, raramente papilosa, e fruto do tipo cápsula com a superfície lisa, verrucosa ou muricada.

Epidendrum no PNCV mostrou-se representado por seis espécies, das 21 registradas para o Estado de Goiás (Barros et al. 2015, BFG 2018, Flora do Brasil 2020, em construção). Tais espécies seguem descritas, ilustradas, comentadas quanto as suas preferências ambientais, relações morfológicas, épocas de floração e frutificação e distribuição geográfica, são contrastadas por meio de uma chave de identificação e ainda alocadas em seis grupos infragenéricos informais propostos por Hágsater (1985), sendo eles a saber:
Grupo Denticulatum (E. secundum), Grupo Difforme (E. campacci), Grupo Aquaticum (E. dendrobioides), Grupo Lanium (E. avicula), Grupo Nocturnum (E. nocturnum) e Grupo Rothii (E. rothii).

Quanto aos ambientes, as espécies crescem como terrícolas em solos ricos em matéria orgânica, e em solos arenosos, pedregosos e argilosos; como rupícolas em afloramentos rochosos, ou epífitas costumeiramente encontradas crescendo junto a liquens e musgos, em geral, associadas a distintas fitofisionomias: cerrado rupestre, campos rupestres, limpos e sujos, matas ciliares, secas e de galeria, e em veredas.

Mendonça et al. (2007) reconheceram oito táxons de Epidendrum para a região de Chapada dos Veadeiros: E. amblostomoides Hoehne, E. aquaticum Lindl., E. dendrobioides Thunb., E. densiflorum Lindl., E. durum var. parviflorum Lindl., E. ellipticum Graham, E. nocturnum Jacq. e $E$. secundum. Entretanto, alguns destes são sinônimos de $E$. dendrobioides (e.g., E. aquaticum, E. durum var. parviflorum) e de E. secundum (e.g., E. ellipticum). Adicionalmente, foram encontradas muitas exsicatas equivocadamente identificadas (incluindo os sinônimos) nos acervos de herbários citados na metodologia, como, por exemplo, $E$. tumuc-humaciense (Veyret) Carnevali \& G.A.Romero, uma espécie ocorrente na região setentrional Sul-Americana (Brasil, Colômbia, Guianas, Suriname e Venezuela), e relacionada a $E$. nocturnum. O mesmo ocorreu com $E$. avicula, E. dendrobioides e E. secundum, identificados, como Lanium avicula (Lindl.) Benth, E. carnosum Lindl. e E. denticulatum Bar. Rodr., respectivamente.

Chave para as espécies de Epidendrum ocorrentes no Parque Nacional da Chapada dos Veadeiros

1. Cauloma não intumescido em pseudobulbo; rizoma inconspícuo; flores com sépalas glabras; polínias monomórficas; frutos com superfície lisa

2. Folhas lanceoladas ou lineares; labelo inteiro

3. Folhas lanceoladas; flores esverdeadas, amarelo-esverdeadas e laranjas; labelo cordiforme, conduplicado com calo inconspícuo, composto por duas lamelas paralelas entre si e justapostas ................................. 3. E. dendrobioides

3. Folhas lineares; flores completamente verdes; labelo oboval, plano com calo conspícuo, composto por 4 quilhas paralelas entre si 5. E. rothii

2. Folhas elípticas, elíptico-lanceoladas, oblongo-elípticas e oval-lanceoladas; labelo 3-lobado ou 4-lobado

4. Flores brancas e róseas com labelo profundamente 3-lobado

5. Caule cilíndrico; flores reunidas em racemos encurtados; brácteas imbricadas; flores 7,5-11,5 cm compr., brancas; pétalas laterais multinervadas; labelo com margem inteira; calo basal, branco, formado por duas lamelas longitudinais paralelas entre si; polínias subtriangulares 4. E. nocturnum

5. Caule compresso; flores reunidas em corimbos; brácteas não imbricadas; flores 1,4-2,5 cm compr., róseas; pétalas laterais 3-nervadas; labelo com margem denticulada; calo central, branco-amarelado, sem lamelas, irregularmente recortado; polínias obovoides 6. E. secundum

4. Flores verdes com labelo 4-lobado 2. E. campacci

1. Cauloma intumescido em pseudobulbo; rizoma conspícuo; flores com sépalas externamente pubescentes; polínias heteromórficas; frutos com superfície verrucosa 1. E. avicula 
1. Epidendrum avicula Lindl. J. Bot. (Hooker) 3: 85. 1841. Figuras 2, 8 a-d

Erva epífita e rupícola, 5-14 cm alt., ereta. Cauloma intumescido em pseudobulbo, não ramificado. Pseudobulbo $1-3,4 \times 0,4-1,5 \mathrm{~cm}$, fusiforme ou oblongoide, verde- arroxeado com máculas arroxeadas. Rizoma 0,3-2,5 cm compr., cilíndrico, conspícuo. Folhas 1-4,4 × 0,4-1,2 cm, elípticas ou elíptico-lanceoladas, ápice obtuso, subcoriáceas, verdes. Racemo ou panícula 2,6-9,5 cm compr., laxa, ereta, pubérula, 4-22 flores. Pedúnculo 1-3,5 cm compr.,

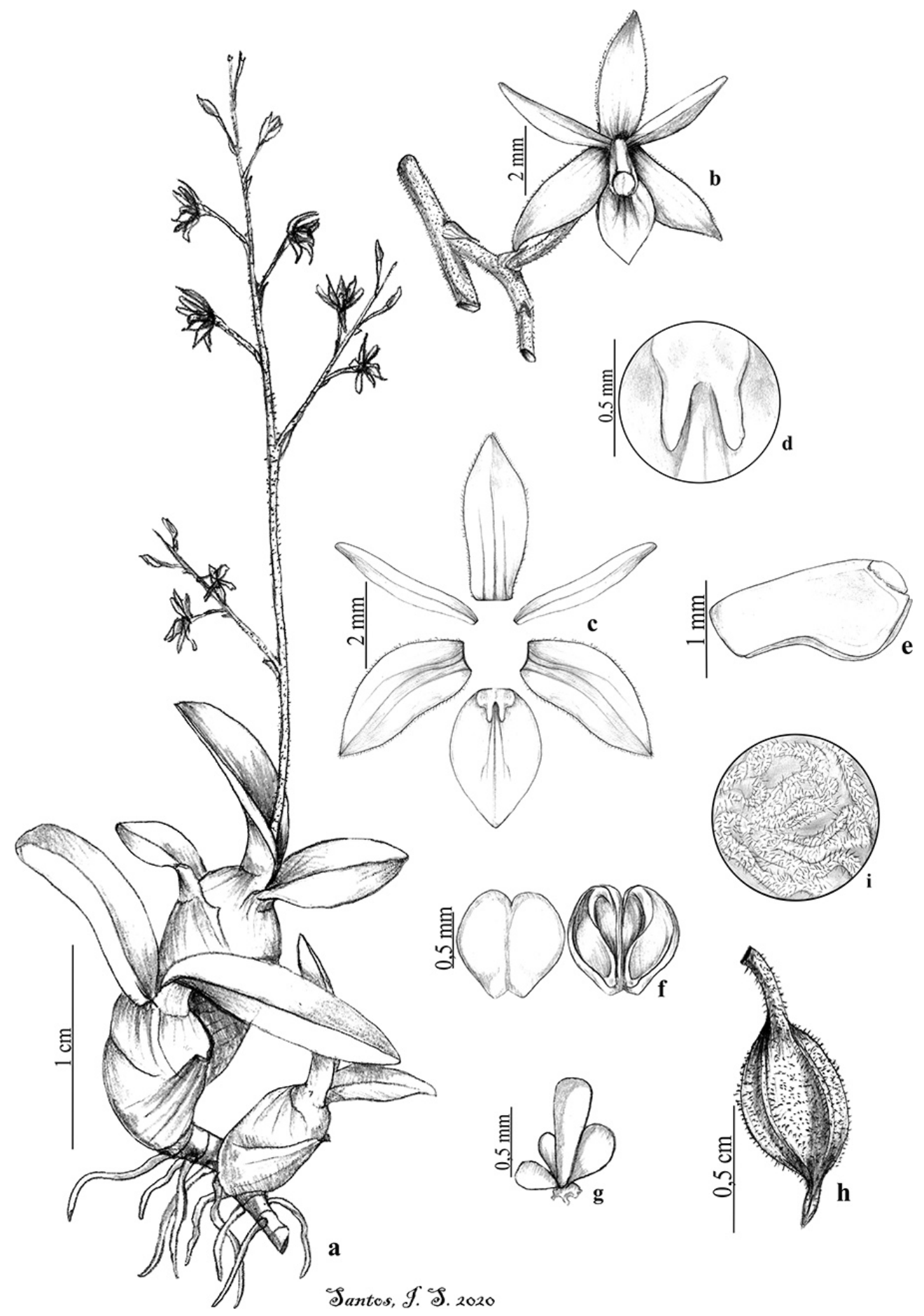

Figura 2. Epidendrum avicula Lindl. a. Hábito. b. Flor. c. Peças florais. d. Detalhe do calo do labelo. e. Coluna. f. Antera em vista dorsal e ventral. g. Polínias. h. Cápsula. i. Detalhe da superfície da cápsula. (I.S. Santos et al. 461).

Figure 2. Epidendrum avicula Lindl. a. Habit. b. Flower. c. Floral pieces. d. Detail of the lip callus. e. Column. f. Anther, dorsal and ventral view. g. Pollinia. h. Capsule. i. Detail of the capsule surface. (I.S. Santos et al. 461). 
raque 1,3-5,4 cm compr. Brácteas triangulares e estreitotriangulares, ápice agudo, membranáceas, não imbricadas, externamente pubescentes; as do pedúnculo $0,2-0,8 \times 0,1$ $1,7 \mathrm{~cm}$; as florais $1,2-4 \times 0,7-2 \mathrm{~mm}$, cobrindo a base do pedicelo. Flores 0,7-1,2 cm compr., creme-esverdeadas. Ovário+pedicelo 3-7 mm compr., pubescentes, castanhoesverdeados. Sépalas castanho-esverdeadas, externamente pubescentes, 3-nervadas; a dorsal 3-5 × 1-1,5 mm, oblongoobovais a oblanceolada, ápice obtuso; as laterais 3-4,5 $\times$ 1-1,5 mm, largamente-subfalcadas, ápice agudo; pétalas laterais 3,2-4,3 × 0,4-0,6 mm, lanceoladas, subfalcadas, ápice agudo, 1-nervadas, creme-esverdeadas, glabras; labelo 2,53,3 $\times 2-2,6 \mathrm{~cm}$, inteiro, largamente oval, plano, 3-nervado, ápice obtuso, membranáceo, glabro, creme-esverdeado; calo presente, menor que $1 \mathrm{~mm}$, inconspícuo, carnoso, formado por uma saliência central e 2 projeções laterais. Coluna 2-2,1 mm compr., glabra, verde-amarelada. Antera ca. $1 \times 1 \mathrm{~mm}$, largamente elíptica, ápice emarginado, alva. Polínias quatro, menores que $1 \mathrm{~mm}$, heteromórficas, obovais, amarelas. Fruto 10-13 × 4-6 mm, elipsoide, verrucoso, pubescente, pendente, verde-arroxeado.

Material examinado: BRASIL. GoIás: Alto Paraíso de Goiás, Parque Nacional da chapada dos veadeiros, 1-VII-2017, fr., I.S. Santos et al. 82 (UFG); idem, ca. de 1,7 km do Morro do Japonês, 22-IX-2017, fl., I.S. Santos et al. 230 (UFG); idem, I.S. Santos et al. 248 (UFG); idem, 16-XII-2017, I.S. Santos et al. 288 (UFG); idem, Morro do Japonês, próximo do bueiro, 27-I-2018, fl., I.S. Santos et al. 376 (UFG); idem, 28-IV-2018, fl., I.S. Santos et al. 461 (UFG); idem, 28-IV2018, fl., I.S. Santos et al. 467 (UFG), idem, a $3 \mathrm{~km}$ de Alto Paraíso de Goiás, em mata de galeria, 29-IX-2018, fr., I.S. Santos et al. 563 (UFG).

Epidendrum avicula distribui-se pela Bolívia, Brasil, Equador e Peru (Govaerts et al. 2020). No Brasil, é referido por Barros et al. (2015) e BFG (2018) para as regiões CentroOeste (DF, GO, MS, MT), Nordeste (AL, BA, CE, PB, PE), Sudeste (ES, MG, RJ, SP) e Sul (PR, RS, SC), abrangendo os domínios fitogeográficos Cerrado e Floresta Atlântica. $\mathrm{Na}$ área de estudo, foi encontrado em matas de galeria e ciliares nas regiões de Alto Paraíso, no Morro do Japonês, Pouso Alto e no Cruzeiro, com flores e frutos entre os meses de dezembro e julho.

Epidendrum avicula é a única dentre as demais congêneres estudadas a possuir o cauloma intumescido em pseudobulbo com máculas arroxeadas, rizoma conspícuo, bainha com pontoações verrucosas, inflorescência em panícula ou racemo com flores creme-esverdeadas com sépalas externamente pubescentes, labelo inteiro, membranáceo, cápsulas verrucosas pubescentes e polínias heteromórficas.

Sistematicamente Epidendrum avicula juntamente com E. microphyllum Lindl., E. stangeanum Rchb.f. e E. stiliferum Dressler, as três últimas não encontradas neste estudo, compõe o Grupo Lanium que inclui plantas pequenas com rizomas conspícuos, cauloma intumescido em pseudobulbos agregados, flores pubescentes, não ressupinadas, e 2-4 polínias heteromórficas, restritas às Américas (Hágsater 1985).

Epidendrum avicula relaciona-se morfologicamente com E. microphyllum e E. stiliferum, com as quais pode ser confundida. Porém, distingue-se de ambas por apresentar folhas elíptico-lanceoladas (vs. ovais e oval-lanceoladas em E. microphyllum, lineares e conduplicadas em E. stiliferum), subcoriáceas, ápice obtuso-acuminado (vs. crassas e coriáceas com ápice agudo), sépala dorsal oblanceolada e oval-lanceolada com ápice obtuso (vs. oblongo-elíptica e elíptico-lanceolada com ápice agudo em E. microphyllum, e elíptica com ápice arredondado em $E$. stiliferum), pétalas laterais oblanceoladas com ápice agudo (vs. lanceoladas e linear-lanceoladas com ápice agudo em E. microphyllum, e oblanceoladas e oblongo-elípticas com ápice arredondado em E. stiliferum).

2. Epidendrum campacci Hágsater \& L. Sánchez. Icon. Orchid. 2: 40, 1993.

Figuras 3, 8 e, $\mathrm{f}$

Erva epífita, 7,4-25 cm alt. ereta. Cauloma 4,8-20 cm compr., não intumescido em pseudobulbo, cilíndrico, levemente flactiflexo, não ramificado. Rizoma $0,3-0,5 \mathrm{~cm}$ compr., cilíndrico, inconspícuo. Folhas 2,2-5,8 × 1-2,3 $\mathrm{cm}$, elípticas e oblongo-elípticas, ápice oblíquo, coriáceas, verdes. Corimbo 5-6,5 cm compr., congesto, ereto, glabro, 7-16 flores. Pedúnculo 1,5-2 cm compr., raque 1,5-1,7 cm. Brácteas imbricadas, ápice agudo, glabras; as do pedúnculo $0,8-1,2 \times 0,5-0,7 \mathrm{~cm}$, lanceoladas e ovais, coriáceas; as florais $0,8-1,7 \times 0,5-0,6 \mathrm{~cm}$, lanceoladas e oval-lanceoladas, membranáceas, ápice agudo cobrindo a base do pedicelo. Flores 3-4,3 cm compr., verde-claras. Ovário+pedicelo 2,2$3 \mathrm{~cm}$ compr., verdes; sépala dorsal $0,8-1,1 \times 0,4-0,5 \mathrm{~cm}$, elíptica, ápice agudo; sépalas laterais $0,8-1,1 \times 0,4-0,5 \mathrm{~cm}$, subfalcadas, ápice agudo; pétalas laterais $1-1,4 \times 0,2 \mathrm{~cm}$, oblanceoladas, 1-nervadas, ápice obtuso; labelo 0,8-0,9 $\times$ 1,4-1,5 cm, transversalmente elíptico, 4-lobado, plano, carnoso na porção central e membranáceo nas margens, verde; lobos anteriores 0,7-0,8 × 0,6-0,7 cm, largamente suborbiculares, margem inteira ou levemente crenada; lobos posteriores $0,3-0,4 \times 0,7-0,8 \mathrm{~cm}$, orbiculares, ápice arredondado; calo ca. $0,1 \times 0,1 \mathrm{~cm}$, carnoso, basal, formado por duas saliências globosas, esverdeadas. Coluna 0,6-0,7 cm compr., glabra, verde. Antera 2,5-2,7 $\times 2 \mathrm{~mm}$, globosa, ápice emarginado, esverdeada. Polínias quatro, 1,6 × 1,3$1,4 \mathrm{~mm}$, obovais, monomórficas, amarelas. Fruto 3,6-4 $\times$ 0,6-0,8 cm, elipsoide, glabro, pendente, verde.

Material examinado: BRASIL. Goiás: Alto Paraíso de Goiás, Parque Nacional da Chapada dos Veadeiros, a 800 $\mathrm{m}$ do Morro da Baleia, 26-IV-2018, fl., I.S. Santos et al. 433 (UFG).

Material examinado adicional: BRASIL. DisTRITo FEDERAL: APA do Gama, Cabeça de Veado, em mata ciliar seca 


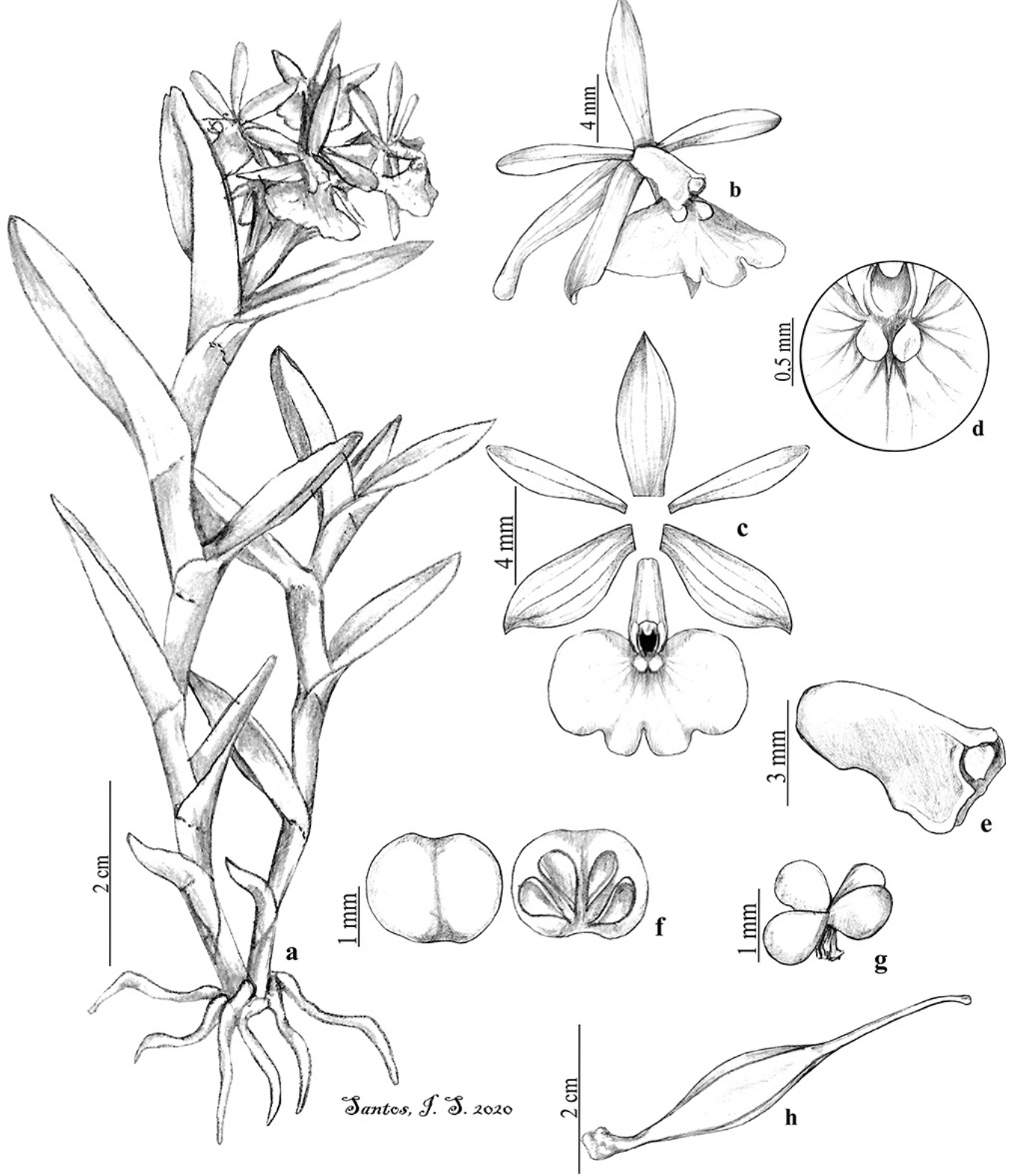

Figura 3. Epidendrum campacci Hágsater \& L. Sánchez. a. Hábito. b. Flor. c. Peças florais. d. Detalhe do calo do labelo. e. Coluna. f. Antera em vista dorsal e ventral. g. Polínias. h. Cápsula. (I.S. Santos et al. 433).

Figure 3. Epidendrum campacci Hágsater \& L. Sánchez. a. Habit. b. Flower. c. Floral pieces. d. Detail of the lip callus. e. Column. f. Anther, dorsal and ventral view. g. Pollinia. h. Capsule. (I.S. Santos et al. 433).

existente na margem do Córrego Taquará, junto à foz do Córrego Tapera, 10-I-1993, fl., B.A.S. Pereira 2360 (K); Reserva Ecológica do Guará, em mata ciliar inundada, 3-I1992, fl., J.A.N. Batista \& L.B. Bianchetti s.n. (CEN26613); Sobradinho, chácara da Dona Marciana, $15^{\circ} 32^{\prime} 19^{\prime \prime}$, 4751'30"O, 1066 m, 17-X-1996, fl., S.M. Gomes \& A.A. Santos 203 (CEN).

Epidendrum campacci é endêmica do Brasil, sendo encontrada nas regiões Centro-Oeste (DF, GO), Nordeste (AL, BA, CE, PB, PE), Sudeste (ES, MG, RJ, SP) e Sul (PR, SC) na Floresta Atlântica e no Cerrado (Barros et al.
2015, BFG 2018, Flora do Brasil 2020, em construção). Na área de estudo, mostrou-se pouco frequente, em matas de ciliares e de galeria do município de Alto Paraíso de Goiás, com flores e frutos entre outubro e maio.

Epidendrum campacci integra um complexo específico denominado Grupo Difforme que inclui aproximadamente 100 espécies, 10 delas brasileiras, caracterizado por incluir plantas cespitosas com ramos carnosos, folhas crassas, inflorescência sem uma espata basal com flores verdes a amarelo-esverdeadas solitárias ou reunidas em corimbos com pétalas e sépalas carnosas, e clinândrio eroso, denticulado 
ou franjado (Hágsater 1985, Stancik et al. 2009, Assis et al. 2013). Pode ser reconhecido pelas folhas elípticas e oblongoelípticas com ápice conspicuamente assimétrico, labelo 4-lobado com lobos anteriores e posteriores suborbiculares e arredondados. Relaciona-se morfologicamente com $E$. ramosum Jacq., espécie não encontrada neste estudo, pelo cauloma não intumescido em pseudobulbo, folhas coriáceas, raramente cartáceas e subcoriáceas com ápice assimétrico e flores esverdeadas. No entanto, E. campacci possui cauloma não ramificado e ereto (vs. ramificado, pendente em E. ramosum), folhas elípticas e oblongo-elípticas (vs. lanceoladas e oblongas), corimbo (vs. racemo), sépalas dorsal e laterais elípticas (vs. oblongo-lanceoladas), pétalas laterais oblanceoladas (vs. lineares), labelo 4-lobado (vs. inteiro, cordiforme).

3. Epidendrum dendrobioides Thunb., Pl. Bras. 2: 17. 1818. Figuras 4, 8 g-j

Erva terrícola, 10-75 cm alt., ereta. Cauloma 9,5-62,5 $\mathrm{cm}$ compr., não intumescido em pseudobulbo, cilíndrico, ramificado ou não. Rizoma $0,8-1 \mathrm{~cm}$ compr., cilíndrico, inconspícuo. Folhas 1-9,5 × 0,4-1,1 cm, lanceoladas, ápice agudo, coriáceas, verde ou verde-amareladas. Panícula ou racemo 8-12,5 cm compr., laxo, ereto, glabro, 4-42 flores. Pedúnculo 1,3-1,5 cm compr., raque $2,5-12 \mathrm{~cm}$ compr. Brácteas não imbricadas, cartáceas; as do escapo, não vistas, as florais $0,1-0,8 \times 0,2-0,3 \mathrm{~cm}$, triangulares, ápice agudo, cobrindo o pedicelo e parte do ovário. Flores 0,8-1,3 cm compr., esverdeadas, amarelo-esverdeadas e laranjas. Ovário+pedicelo 0,3-0,4 cm compr., verdes. Sépalas, carnosas, ápice agudo, glabras, esverdeadas a amarelo-esverdeadas e laranjas; a dorsal 0,6-0,8 × 0,2-0,3 $\mathrm{cm}$, oblongo-elíptica, côncava, ápice agudo; as laterais 0,6-0,8 $\times 0,3-0,4 \mathrm{~cm}$, elíptico-falcadas, côncavas; pétalas laterais $0,5-0,7 \times 0,1 \mathrm{~cm}$, oblanceoladas, margem inteira, 1-nervadas, ápice obtuso, glabras; labelo 0,5-0,6 × 0,6-0,7 $\mathrm{cm}$, inteiro, conduplicado, cordiforme, margem inteira, ápice agudo, carnoso, glabro; calo presente, menor que $1 \mathrm{~mm}$, inconspícuo, delgado, formado por duas lamelas paralelas entre si, e justapostas distalmente. Coluna 0,4-0,5 cm compr., glabra, verde-alva. Antera orbicular, ca. $1 \times 1$ $\mathrm{mm}$, ápice arredondado, alva. Polínias quatro, obovoides, menores que $1 \mathrm{~mm}$, monomórficas, amarelas. Fruto 1,52,5 $\times 1,1-1,3 \mathrm{~cm}$, elipsoide, ereto, glabro, verde-amarelado.

Material examinado: BRASIL. Goís: Alto Paraíso de Goiás, Parque Nacional da Chapada dos Veadeiros, Cruzeiro, $23 \mathrm{~km}$ de Alto Paraíso em direção a Teresina de Goiás, 1356'39"S, 47029'38"W, 1410 m, 13-XI-1996, f1., M.A. Silva \& A.J.V. Santos 3256 (CEN); próximo a um veio d'água, 4-I-1972, fl., J.A. Rizzo 7399 (UFG); idem, na beira do córrego, 4-II-1972, fl., J.A. Rizzo 7587 (UFG); 30-VI-2017, fr., I.S. Santos et al. 26 (UFG); idem, $1,7 \mathrm{~km}$ do Morro do Japonês, 22-IX-2017, fl., fr., I.S. Santos et al. 234 (UFG); idem, Cavalcante, próximo ao córrego da mata de galeria, 135'ㄷㄴ"S, 47026'30"W, 1450 m, 23-IX-2017, fr., I.S. Santos et al. 255 (UFG); idem, 15-XII-2017, fl., I.S. Santos et al. 271 (UFG); idem, Morro do Japonês, próximo do bueiro, 27-I-2018, fl., I.S. Santos et al. 363 (UFG); idem, Cruzeiro, ca. $350 \mathrm{~m}$ da casa abandonada, $13^{\circ} 56^{\prime} 44^{\prime \prime} \mathrm{S}, 47^{\circ} 29^{\prime} 48^{\prime \prime} \mathrm{W}$, 1480 m, 24-II-2018, fl., fr., I.S. Santos et al. 416 (UFG); s.d. fl., M.J. Silva 7645 (UFG); Cavalcante, a esquerda da GO-118, sentido Alto Paraíso-Terezinha de Goiás, no final da cerca que limita o parque na sua porção Leste, $13^{\circ} 55^{\prime} 15,3^{\prime \prime} \mathrm{S}$, 47²5'31,1"W, 1420 m, 4-I-2015, fl., R.C. Sodré, M.J. Silva \& C.H.G.M. Filho 1619 (UFG).

Epidendrum dendrobioides se distribui pela Colômbia, Equador e Venezuela (Jørgensen \& Ulloa 1994, Stancik et al. 2009, Idárraga-Piedrahita et al. 2011). No Brasil, conforme Barros et al. (2015) e BFG (2018), ocorre de norte a sul: Centro-Oeste (DF, GO, MS, MT), Norte (TO), Nordeste (BA), Sudeste (ES, MG, RJ, SP) e Sul (PR), nos domínios fitogeográficos Cerrado e Floresta Atlântica. Neste estudo, mostrou-se frequente em campos úmidos, nas margens de matas de galeria e ciliares, e próximo a cursos d'água e de veredas, com flores e frutos entre agosto e fevereiro.

Epidendrum dendrobioides é a única espécie da região com labelo cordiforme e conduplicado, e cápsulas eretas, o que a torna facilmente reconhecida e inconfundível em relação às demais espécies. Adicionalmente, a mesma possui cauloma não intumescido em pseudobulbo, cilíndrico, às vezes ramificado com folhas lanceoladas, flores esverdeadas a laranjadas com pétalas e sépalas crassas, labelo inteiro, conduplicado, cordiforme e cápsulas eretas e glabras.

Esta espécie pertence ao Grupo Aquaticum, o qual, conforme Hágsater (1985), Stancik et al. (2009) e Hágsater \& Santiago (2018), inclui plantas com inflorescências em panículas, peças florais coriáceas, labelo largamente 3-lobado, cordiforme e conduplicado, com tricomas presentes ou ausentes no disco e/ou no interior do nectário. Este grupo compreende aproximadamente 20 espécies, cuja morfologia floral e aspectos vegetativos são muito similares (Hágsater \& Sánchez 2010, 2015, Hágsater \& Santiago 2018, 2020). Destas, E. tundaymense Hágsater, E. Santiago \& Tobar, táxon endêmico do Equador (Hágsater \& Santiago 2018), relaciona-se morfologicamente com $E$. dendrobioides. Ambas apresentam caule cilíndrico e flores amareladas com labelo cordiforme e conduplicado. Todavia, E. dendrobioides apresenta folhas lanceoladas (vs. ovallanceoladas em E. tundaymense), pétalas oblanceoladas 1-nervadas (vs. oblongo-elíptica, 3-nervadas), assim como nectário e disco do labelo glabros (vs. pubescentes).

4. Epidendrum nocturnum Jacq. Enum. Syst. Pl. 29. 1760. Figuras 5, 8 k, 1, 9 a, b

Erva rupícola ou epífita, 10-65 cm alt., ereta. Cauloma 7-60 cm compr., não intumescido em pseudobulbo, compresso, não ramificado. Rizoma $0,6-1,3 \mathrm{~cm}$ compr., cilíndrico, inconspícuo. Folhas 1,5-15× 1-3,4 cm, elípticolanceoladas, oblongo-elípticas, cartáceas, ápice oblíquo, verde-arroxeadas. Racemo 1-4 cm compr., laxo, ereto, 


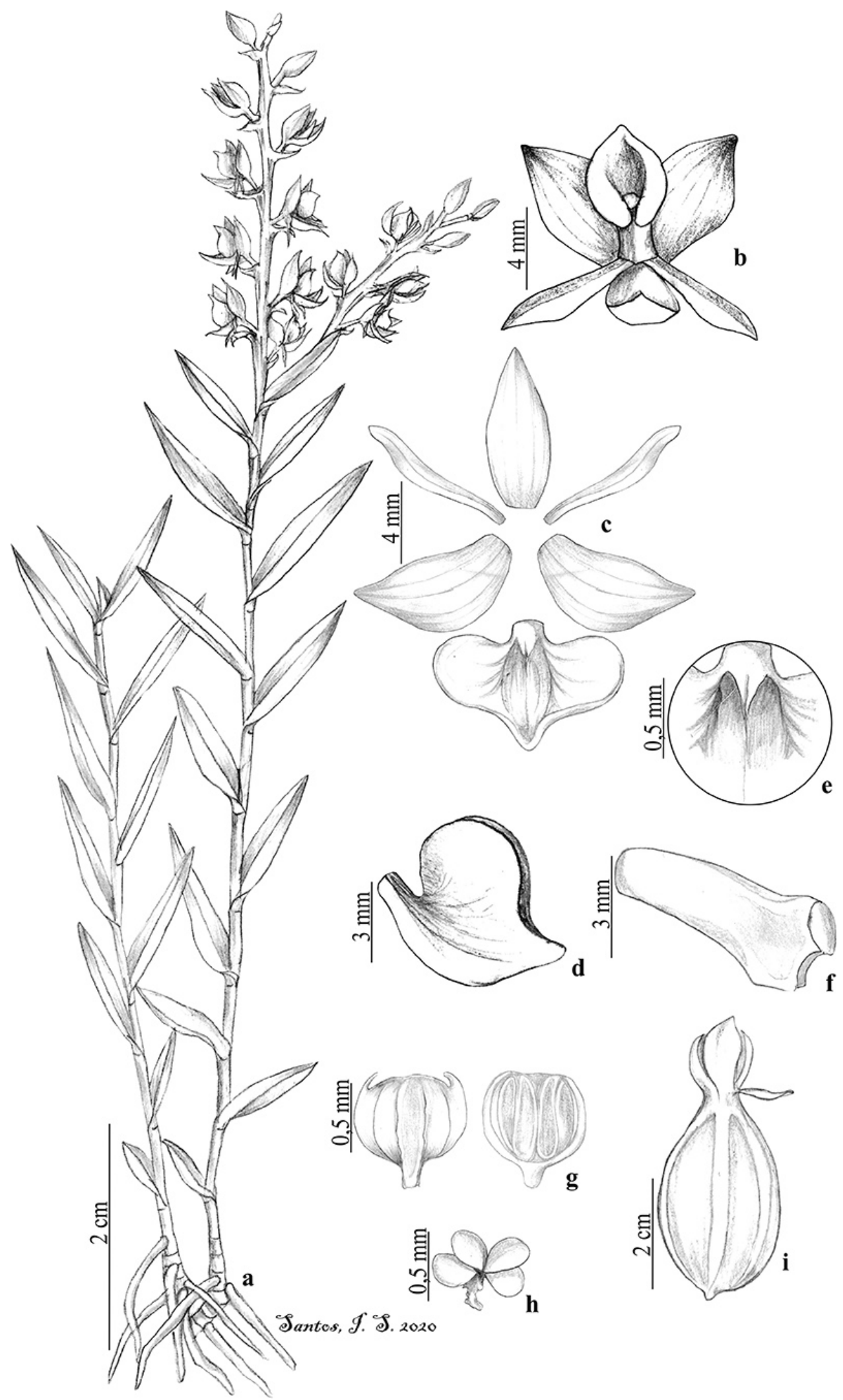

Figura 4. Epidendrum dendrobioides Thunb. a. Hábito. b. Flor. c. Peças florais. d. Labelo em vista lateral. e. Detalhe do calo do labelo. f. Coluna. g. Antera em vista dorsal e ventral. h. Polínias. i. Cápsula. (I.S. Santos et al. 416).

Figure 4. Epidendrum dendrobioides Thunb. a. Habit. b. Flower. c. Floral pieces. d. Lip, lateral view. e. Detail of the lip callus. f. Column. g. Anther, dorsal and ventral view. h. Pollinia. i. Capsule. (I.S. Santos et al. 416). 


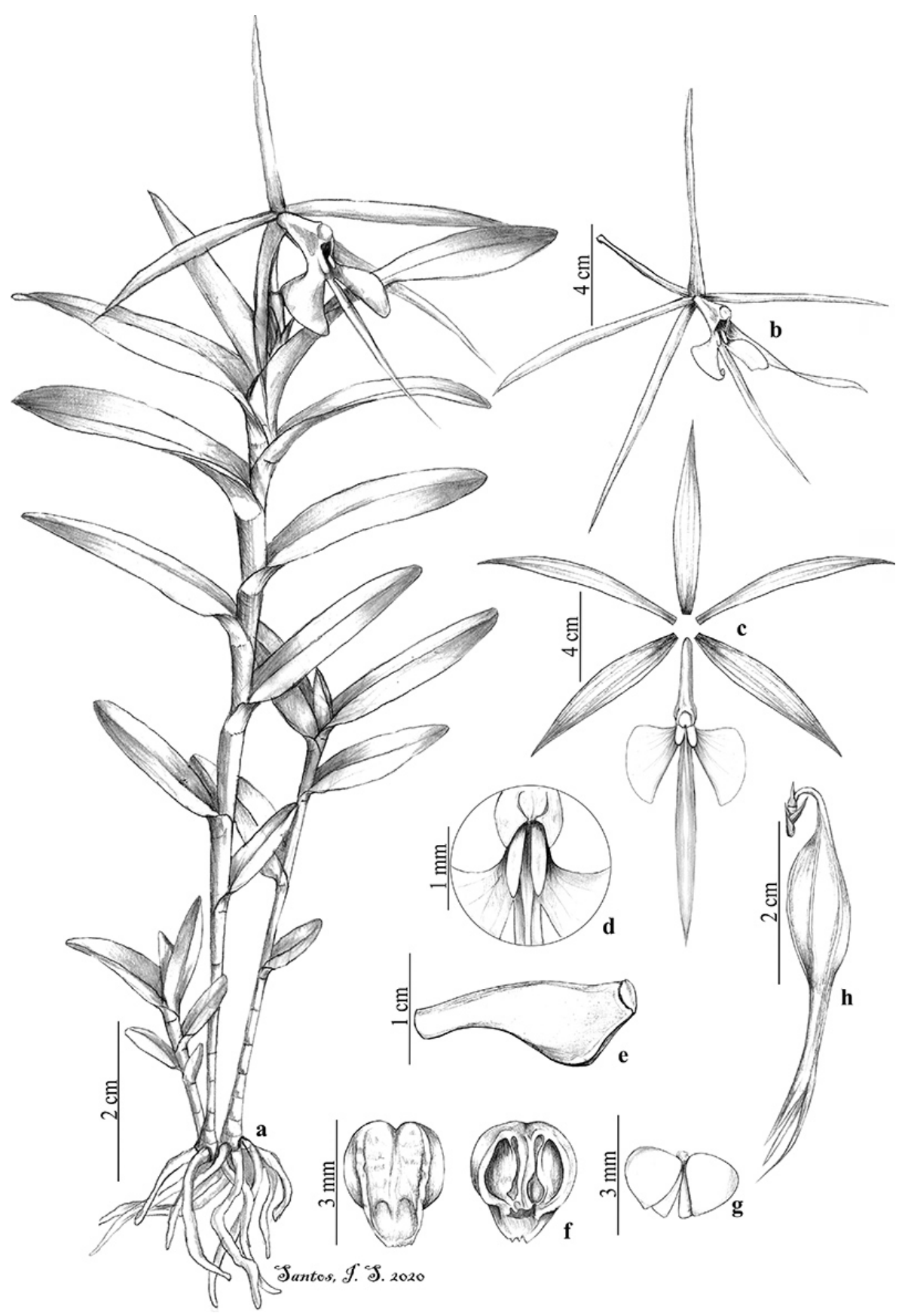

Figura 5. Epidendrum nocturnum Jacq. a. Hábito. b. Flor. c. Peças florais. d. Detalhe do calo do labelo. e. Coluna. f. Antera em vista dorsal e ventral. g. Polínias. h. Cápsula. (I.S. Santos et al. 412).

Figure 5. Epidendrum nocturnum Jacq. a. Habit. b. Flower. c. Floral pieces. d. Detail of the lip callus. e. Column. f. Anther, dorsal and ventral view. g. Pollinia. h. Capsule. (I.S. Santos et al. 412).

glabro, 1-4 flores. Pedúnculo 0,4-1 cm compr., raque 2,7-3 cm. Brácteas cartáceas, imbricadas, triangulares, ápice agudo, glabras; as do pedúnculo 0,6-1 × 0,5-0,8 $\mathrm{cm}$; as florais $0,2-7 \times 0,2-0,8 \mathrm{~cm}$, ápice agudo, cobrindo a base do pedicelo. Flores 7,5-11,5 cm compr., brancas. Ovário+pedicelo 2-6,8 cm compr., verde-arroxeados. Sépalas glabras, creme-esverdeadas; a dorsal 5-5,1 $\times 0,5-0,6 \mathrm{~cm}$, estreito-elíptica, ápice agudo; as laterais 5,3-5,4 × 0,5-0,6 cm, estreito-elípticas ou subfalcadas, ápice agudo; pétalas laterais 3,5-5,4 × 0,4-0,5 cm, lanceoladas, multi-nervadas, ápice agudo, glabras, creme-esverdeadas; labelo 2,5-4,2 × 1-1,4 $\mathrm{cm}$, profundamente 3-lobado, plano, pouco carnoso, glabro, branco; lobos laterais 0,7-1,7 $\times 0,5-1 \mathrm{~cm}$, suborbiculares, margem inteira; lobo mediano 2,5-3,6 $\times 0,8-0,9 \mathrm{~cm}$, oblongolanceolado ou linear-lanceolado, ápice agudo; calo ca. $0,2-0,5 \times 0,1-0,2 \mathrm{~cm}$, carnoso, basal, formado por duas 
lamelas longitudinais paralelas, brancas. Antera $3 \times 2 \mathrm{~mm}$, oval, 2-costada, ápice truncado e irregularmente recortado, branco-esverdeada. Coluna 1,2-2,4 cm compr., glabra, verde-alva. Polínias quatro, $1,5 \times 1,5 \mathrm{~mm}$, subtriangulares, monomórficas, amarelas. Fruto $6-8 \times 2-2,5 \mathrm{~cm}$, elipsoide, glabro, pendente, verde-arroxeado.

Material examinado: BRASIL. Goiás: Alto Paraíso de Goiás, Parque Nacional da Chapada dos Veadeiros, ca. de $2 \mathrm{~km}$ da bifurcação da estrada que leva às Sete Quedas do Rio Preto, ca. de 3,5 km ao norte da GO-239, cerrado rupestre perto de córrego, $14,6^{\circ} 18,6^{\prime} 00^{\prime \prime} \mathrm{S}, 47^{\circ} 44^{\prime} 11,5^{\prime \prime} \mathrm{W}$, 15-II-2015, fl., M.J. Silva et al. 6436 (UFG); próximo da vereda do PNCV, perto da entrada para o Alojamento Lobo Guará, próximo ao córrego, 1-VII-2017, fl., I.S. Santos et al. 67 (UFG); idem, 1-VII-2017, fr., I.S. Santos et al. 72 (UFG); idem, ca. 1,7 km do Morro do Japonês, 22-IX-2017, I.S. Santos et al. 231 (UFG); idem, $1^{\circ} 01^{\prime} 51^{\prime \prime S}, 47^{\circ} 31^{\prime} 50^{\prime \prime} \mathrm{W}$, 1446 m, 22-IX-2017, I.S. Santos et al. 251 (UFG); idem, Cavalcante, próximo ao córrego da mata de galeria, $13^{\circ} 55^{\prime} 55^{\prime \prime} \mathrm{S}, 47^{\circ} 26^{\prime} 30^{\prime \prime W}, 1455$ m, 23-IX-2017, I.S. Santos et al. 263 (UFG); idem, Salto dos 80, próximo à mata de galeria, 26-I-2018, fl., I.S. Santos et al. 348 (UFG); idem, Cruzeiro, próximo ao córrego, 24-II-2018, fl., I.S. Santos et al. 412 (UFG); idem, Alto Paraíso, próximo à estrada, $14^{\circ} 04^{\prime} 14,5^{\prime \prime} \mathrm{S}, 47^{\circ} 30^{\prime} 40,1^{\prime \prime} \mathrm{W}, 1343$ m, 24-VIII-2018, fr., I.S. Santos et al. 505 (UFG).

Epidendrum nocturnum se distribui desde o Sul da Flórida até a América Tropical (Govaerts et al. 2020). No Brasil é referida para todas as regiões, sobretudo, nos domínios fitogeográficos Amazônia, Cerrado e Floresta Atlântica (Barros et al. 2015, BFG 2018, Flora do Brasil 2020, em construção). Neste estudo foi encontrada, como epífita ou rupícola, em matas de galeria e ciliares, e em cerrados rupestres de Alto Paraíso de Goiás, no Cruzeiro, Pouso Alto, no Morro do Japonês, nas Sete Quedas do Rio Preto e nos Saltos.

Epidendrum nocturnum, quando comparada as demais espécies registradas neste estudo, pode ser seguramente identificada pela associação dos seguintes caracteres: cauloma compresso, não intumescido em pseudobulbo, flores brancas com pétalas e sépalas longas e estreitas, membranáceas e multinervadas, labelo 3-partido com um calo basal constituído por duas lamelas paralelas entre sí, e cápsulas pendentes e glabras. Foi encontrada com flores e frutos entre julho e fevereiro, sendo mais frequentes em meses chuvosos.

Epidendrum nocturnum assemelha-se a E. carpophorum Barb. Rodr., uma espécie amplamente distribuída pela região Neotropical (Govaerts et al. 2020). Ambas apresentam uma morfologia vegetativa semelhante. Entretanto, podem ser diferenciadas principalmente por sua morfologia floral. E. nocturnum apresenta flores brancas (vs. flores cremes, levemente castanhas em E. carpophorum), e lamelas que constituem o calo do labelo retangulares (vs. fusiformes).
Em termos de classificação, Hágsater (1985) posicionou E. nocturnum no Grupo Nocturnum, o qual segundo o autor compreende aproximadamente 50 espécies neotropicais reconhecidas pelos ramos caniculados, flores brancas com formato de estrela, aromáticas durante a noite, reunidas em racemos curtos sucessivos, labelo 3-lobado com lobo mediano linear-triangular ou acicular, pétalas e sépalas longas e estreitas, e espata ausente na base do pedúnculo (Carnevali \& Romero 1996, Hágsater \& Soto 2003, Stancik et al. 2009, Assis et al. 2013, Kolanowska \& Mystkowska 2014).

5. Epidendrum rothii A.D. Hawkes. Orquídea (Rio de Janeiro). 18(5): 173, 178. 1956[1957].

Figuras 6, $9 \mathrm{c}$

Erva epífita, 12,9-33 cm alt., ereta. Cauloma 8-24 cm compr., não intumescido em pseudobulbo, cilíndrico, não ramificado. Rizoma 0,2-0,3 cm compr., cilíndrico, inconspícuo. Folhas 4,2-9,5 × 0,3-0,4 cm, lineares, ápice agudo, cartáceas, verdes. Racemo $3-5 \mathrm{~cm}$ compr., laxo, ereto, glabro, 13-25 flores. Pedúnculo 1-2,4 cm compr., raque 3,4$7,1 \mathrm{~cm}$ compr. Brácteas não imbricadas, cartáceas, glabras; as do pedúnculo $0,8-1,1 \times 0,4-0,5 \mathrm{~cm}$; as florais $0,2-0,3 \times$ 0,1-0,2 cm, deltoides, cobrindo o pedicelo, ápice agudo. Flores 1,8-2 cm compr., verde-amareladas. Ovário+pedicelo 0,6-0,8 $\times 0,2-0,3 \mathrm{~cm}$ compr., verdes. Sépalas crassas, glabras; a dorsal $12 \times 4-5 \mathrm{~mm}$, elíptica-oboval, ápice agudo; as laterais 10-12 × 3-4 mm, elíptico-subfalcadas, ápice agudo; pétalas laterais 10-11 ×0,9-1 mm, lineares, membranáceas, ápice agudo, 1-nervadas, glabras, verdes; labelo $12 \times 8 \mathrm{~mm}$, inteiro, plano, oboval, margem inteira, ápice obtuso ou truncado, glabro; calo. $4-5 \mathrm{~mm}$ compr., formado por 4 quilhas paralelas entre si, desde a base ao terço superior. Coluna 0,7-0,9 cm compr., glabra, verde. Antera ca. 1,3-1,5 × 1-2 $\mathrm{mm}$, arredondada, ápice arredondado, esverdeada. Polínias quatro, ca. $1 \times 0,5 \mathrm{~mm}$, clavadas, monomórficas, amarelas. Fruto ca. 1,9 9 0,8 cm, elipsoide, glabro, pendente, verde.

Material examinado: BRASIL. GoIÁs: Alto Paraíso de Goiás, Parque Nacional da Chapada dos Veadeiros, Rio dos Couros, próximo ao córrego que corta a mata, 25-VIII-2018, fl., I.S. Santos et al. 535 (UFG).

Material examinado adicional: BRASIL. DisTRITO FEDERAL: Mata ciliar próxima da FERCAL, 21-XII-1989, fl., L.B. Bianchetti s.n. (CEN14954); GoIÁs: Luziânia, margem esquerda do lago, cerca de 1,5 km após a Barragem (montante), 16 $6^{\circ} 19^{\prime} 49^{\prime \prime} \mathrm{S}, 48^{\circ} 12^{\prime} 14^{\prime \prime} \mathrm{O}, 832 \mathrm{~m}, 30$-III-2005, fr., A.A. Santos \& J.B. Pereira 2571 (CEN); Serra dos Pireneus, ca. 18 km E. of Pirenópolis, 1000 m, 18-I-1972, fr., H.S. Irwin et al. 34506 (UB).

Espécie registrada no Brasil e na Colômbia (Hágsater \& Sánchez 2010, Zanatta 2012), sendo no primeiro país citada para o domínio fitogeográfico Cerrado na região CentroOeste (GO, DF). Foi encontrada em mata de galeria na região de Alto Paraíso de Goiás como epífita com flores em 


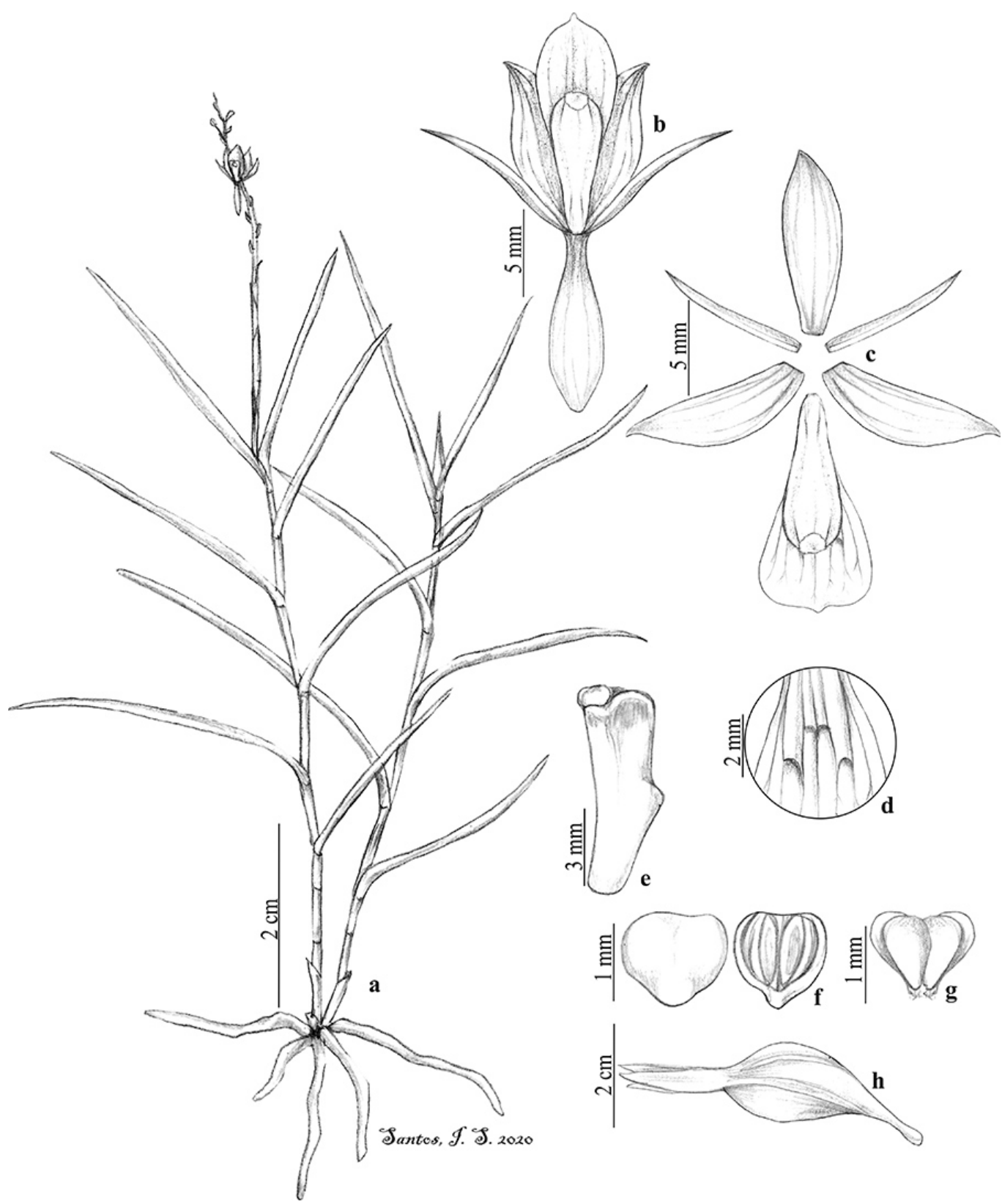

Figura 6. Epidendrum rothii A.D. Hawkes. a. Hábito. b. Flor. c. Peças florais. d. Detalhe do calo do labelo. e. Coluna. f. Antera em vista dorsal e ventral. g. Polínias. h. Cápsula. (I.S. Santos et al. 535).

Figure 6. Epidendrum rothii A.D. Hawkes. a. Habit. b. Flower. c. Floral pieces. d. Detail of the lip callus. e. Column. f. Anther, dorsal and ventral view. g. Pollinia. h. Capsule. (I.S. Santos et al. 535).

agosto. Pode ser reconhecida pelo cauloma não intumescido em pseudobulbo, folhas lineares, flores verdes com sépalas e pétalas rígidas, sendo as últimas filiformes, o labelo inteiro, oboval-cuneado com calo constituído por 4 quilhas paralelas entre si, até mais da metade do labelo.

Epidendrum rothii foi posicionada por Hágsater \& Sánchez (2010) no monoespecífico Grupo Rothii, o qual, segundo os autores, é marcado por incluir plantas cespitosas com labelo caloso, composto por 4 quilhas paralelas entre si. O Grupo Rothii, relaciona-se morfologicamente ao Grupo Anceps, e ao subgrupo Polyanthum por serem compostos por plantas cespitosas com flores reunidas em racemos. Entretanto, este subgrupo difere dos demais por apresentar folhas largas e labelo 3-lobado. Adicionalmente, E. rothii compartilha de ramos delgados, folhas lineares e flores dispostas em racemos laxos com E. angustissimum Lindl., espécie ocorrente na Colômbia e no Equador, e $E$. ramosissimum Ames \& C. Schweinf., um táxon endêmico da Costa Rica (Hágsater \& Sánchez 2010, Govaerts et al. 2020), diferindo-se destas por não apresentar caule ramificado (vs. 
ramificado em E. ramosissimum), seus racemos são eretos (vs. pendentes em E. angustissimum), o labelo é inteiro (vs. 3-lobado em E. angustissimum) e oboval-cuneado (vs. cordiforme em E. ramosissimum).

6. Epidendrum secundum Jacq. Enum. Syst. Pl. 29. 1760. Figuras 7, 9 d-i
Erva terrícola e rupícola, 4-50 cm alt., ereta. Cauloma 3-42 cm compr., não intumescido em pseudobulbo, cilíndrico, não ramificado. Rizoma 0,5-0,7 cm compr., cilíndrico, inconspícuo. Folhas 0,5-10 × 0,4-3,4 cm, elípticas, oblongoelípticas, ápice arredondado ou obtuso, coriáceas, verdes. Corimbo 16,3-80 cm compr., congesto, ereto, glabro, 10-68 flores. Pedúnculo 13-69 cm compr., raque 1,6-17 cm compr.

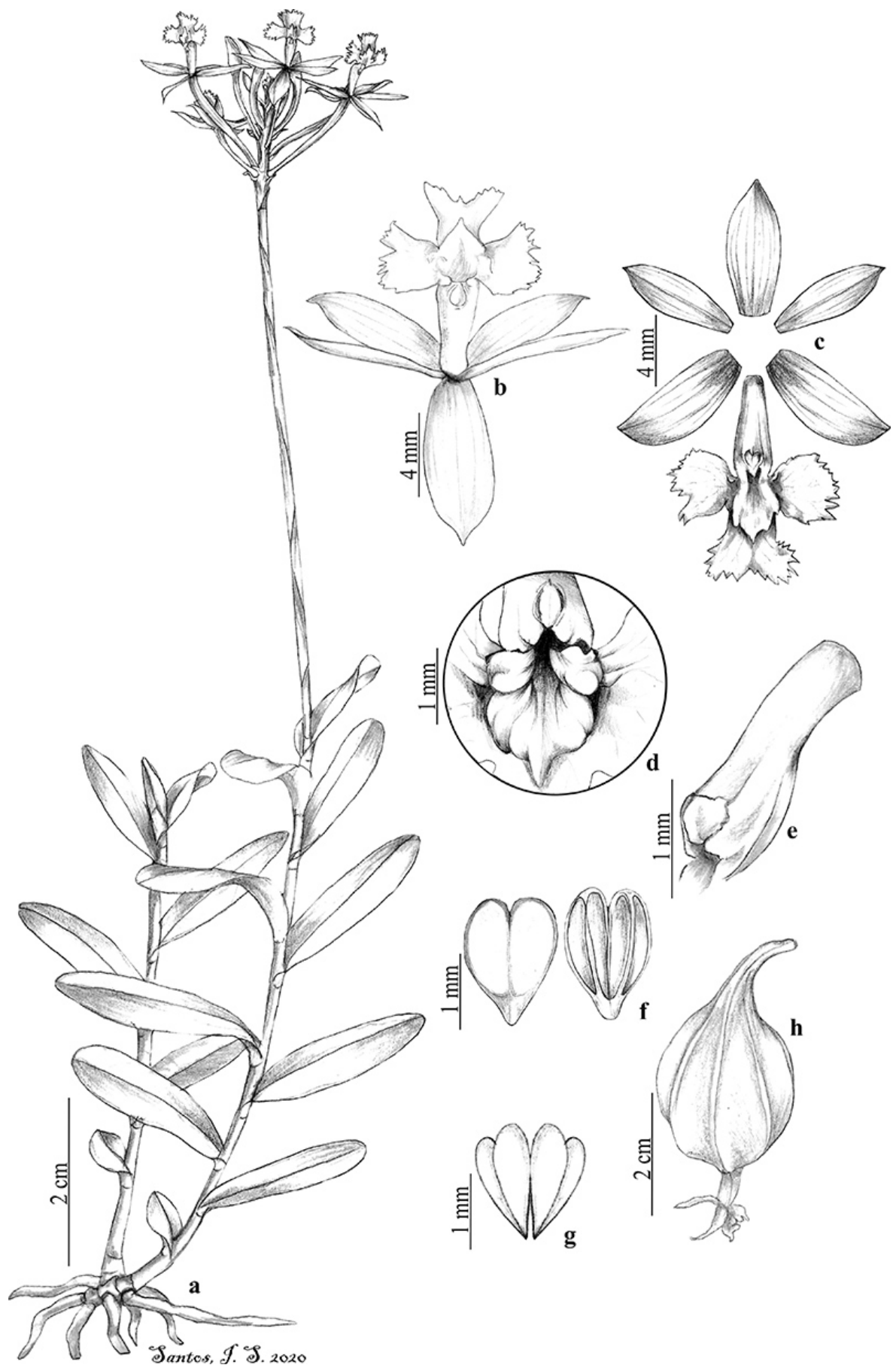

Figura 7. Epidendrum secundum Jacq. a. Hábito. b. Flor. c. Peças florais. d. Detalhe do calo do labelo. e. Coluna. f. Antera em vista dorsal e ventral. g. Polínias. h. Cápsula. (I.S. Santos et al. 262).

Figure 7. Epidendrum secundum Jacq. a. Habit. b. Flower. c. Floral pieces. d. Detail of the lip callus. e. Column. f. Anther, dorsal and ventral view. g. Pollinia. h. Capsule. (I.S. Santos et al. 262). 

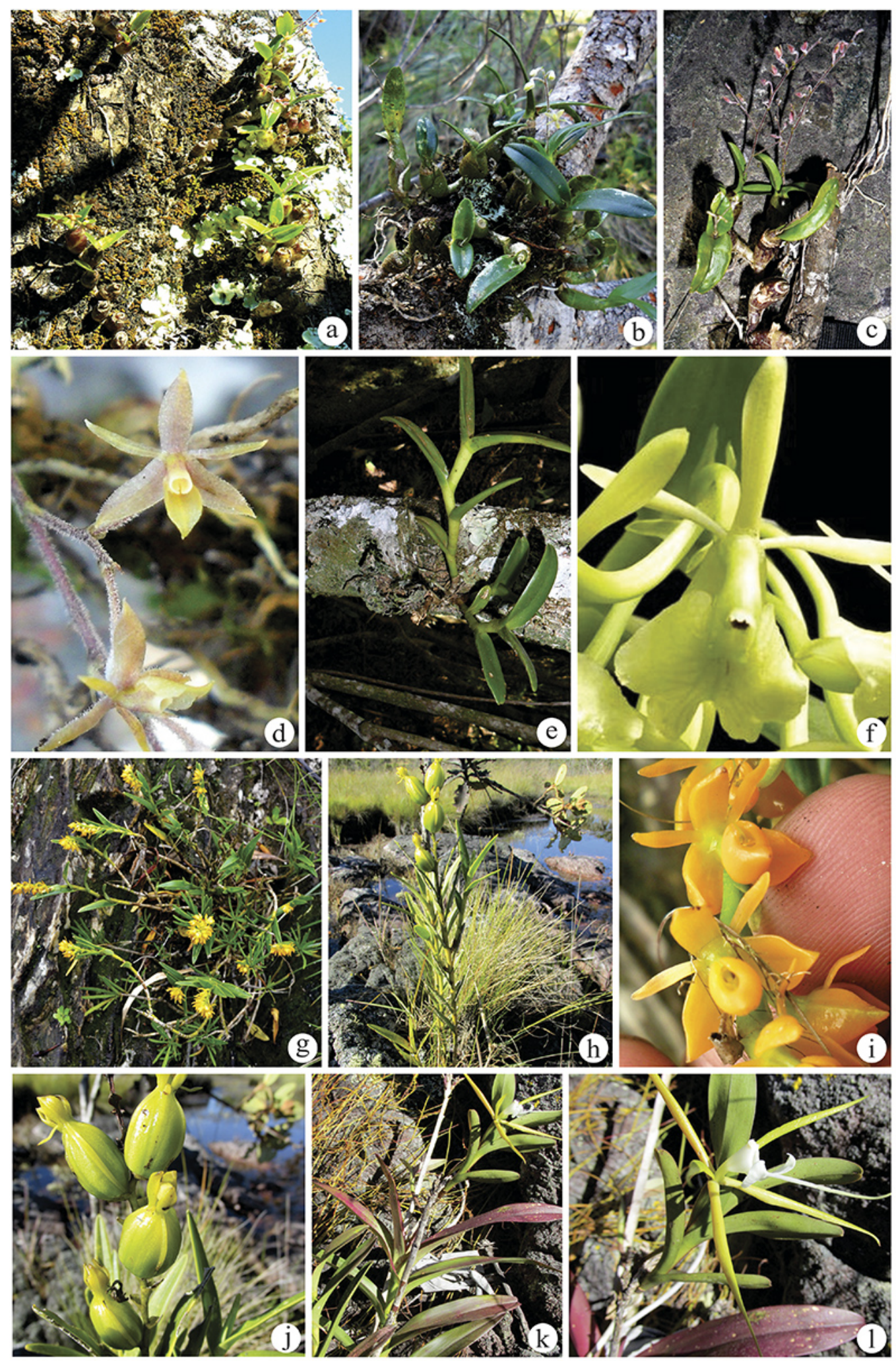

Figura 8. Espécies de Epidendrum ocorrentes no Parque Nacional da Chapada dos Veadeiros, Estado de Goiás, Brasil. a-d. Epidendrum avicula Lindl. e, f. E. campacci Hágsater \& L. Sánchez. g-j. E. dendrobioides Thunb. k, 1. E. nocturnum Jacq. a-c, e, g, h, k. Hábito. d, f, i, 1. Flores. j. Cápsulas.

Figure 8. Epidendrum species occurring in the Parque Nacional da Chapada dos Veadeiros, Goiás State, Brazil. a-d. Epidendrum avicula Lindl. e, f. E. campacci Hágsater \& L. Sánchez. g-j. E. dendrobioides Thunb. k, 1. E. nocturnum Jacq. a-c, e, g, h, k. Habit. d, f, i, 1. Flowers. j. Capsules. 

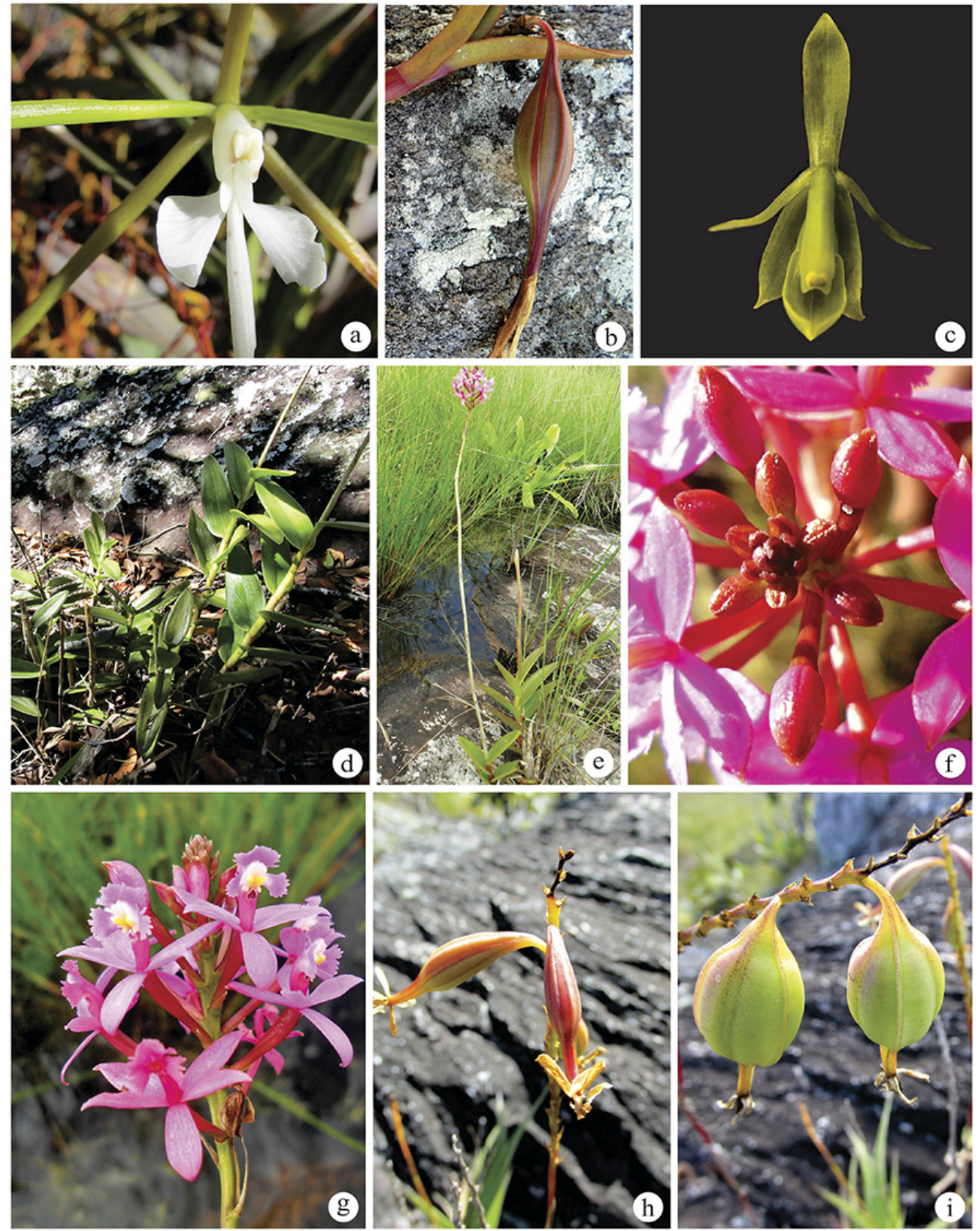

Figura 9. Espécies de Epidendrum ocorrentes no Parque Nacional da Chapada dos Veadeiros, Estado de Goiás, Brasil. a, b. E. nocturnum Jacq. c. E. rothii A.D. Hawkes. d-i. E. secundum Jacq. a, c, f, g. Flores e botões. b, h, i. Cápsulas. d, e. Hábito.

Figure 9. Epidendrum, species occurring in the Parque Nacional da Chapada dos Veadeiros, Goiás State, Brazil. a, b. E. nocturnum Jacq. c. E. rothii A.D. Hawkes. d-i. E. secundum Jacq. a, c, f, g. Flowers and buds. b, h, i. Capsules. d, e. Habit.

Brácteas cartáceas, não imbricadas, glabras; as florais 0,2-4× $0,1-0,7 \mathrm{~cm}$, triangulares, cobrindo a base do pedicelo, ápice agudo; as do pedúnculo 1,3-5 × 0,3-0,7 cm. Flores 1,4-2,5 $\mathrm{cm}$ compr., róseas. Ovário+pedicelo $0,3-1,8 \mathrm{~cm}$ compr., verde-arroxeados. Sépalas membranáceas, glabras; a dorsal 5-8 $\times$ 2-3,2 mm, oblanceolada ou oblongo-elíptica, ápice agudo; as laterais 6-8 × 2-4 mm, oblongo-subfalcadas, ápice agudo; pétalas laterais 5-8 × 1-3,5 mm, elípticas, 3-nervadas, ápice obtuso, membranáceas; labelo 3,3-7,3 × 3,8-8 mm, 3-lobado, plano, glabro, róseo-amarelado; lobos laterais 2-4 $\times$ 2,5-4 mm, suborbiculares, margem denticulada; lobo mediano 0,3-0,6 0 0,3-0,6 cm, deltoide, margem denticulada; calo 1-3 $\times 1-2 \mathrm{~mm}$, amarelado, inteiro, recortado, carnoso. Coluna 3-4 mm compr., glabra, rósea. Antera ca. $2 \times 2$, oboval, ápice emarginado, verde-arroxeada. Polínias quatro, obovoides, monomórficas, amarelas. Fruto ca. 3-4 × 1-2,6 
cm, ovoide-elíptico, glabro, pendente, verde-amarelado e levemente arroxeado.

Material Examinado: BRASIL. Goiás: Alto Paraíso de Goiás, Parque Nacional da Chapada dos Veadeiros, 30VI-2017, fr., I.S. Santos et al. 49 (UFG); idem, próximo da vereda do PNCV, perto da entrada para o Alojamento Lobo Guará, próximo ao córrego, 1-VII-2017, fl., I.S. Santos et al. 64 (UFG); idem, 1-VII-2017, fr., I.S. Santos et al. 68 (UFG); idem, 22-VII-2017, I.S. Santos et al. 145 (UFG); idem, nas proximidades da estrada que leva ao Alojamento Lobo Guará, 21-IX-2017, fl., I.S. Santos et al. 217 (UFG); idem, a 1,7 km da estrada, $14^{\circ} 02^{\prime} 18^{\prime \prime} \mathrm{S}, 47^{\circ} 32^{\prime} 20^{\prime \prime} \mathrm{W}, 1436 \mathrm{~m}, 22-\mathrm{IX}-2017$, fr., I.S. Santos et al. 253 (UFG); idem, Cavalcante, próximo ao córrego da mata de galeria, $13^{\circ} 55^{\prime} 55^{\prime \prime} \mathrm{S}, 47^{\circ} 26^{\prime} 30^{\prime \prime} \mathrm{W}$, 1455 m, 23-IX-2017, fl., fr., I.S. Santos et al. 262 (UFG); idem, Cruzeiro, próximo ao córrego, ca. de $350 \mathrm{~m}$ da casa abandonada, $13^{\circ} 56^{\prime} 44^{\prime \prime} \mathrm{S}, 47^{\circ} 29^{\prime} 48^{\prime \prime} \mathrm{W}, 1480 \mathrm{~m}, 24-\mathrm{II}-2018$, fl., I.S. Santos et al. 417 (UFG); idem, sobre rochas, 24-II2018, fl., I.S. Santos et al. 432 (UFG); idem, a $500 \mathrm{~m}$ do

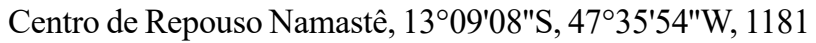
m, 27-IV-2018, fl., fr., I.S. Santos et al. 455 (UFG); idem, Alto Paraíso, $14^{\circ} 04^{\prime} 14,5^{\prime \prime S}, 47^{\circ} 30^{\prime} 40,1 " \mathrm{~W}, 1343 \mathrm{~m}, 26-\mathrm{V}$ 2018, fl., fr., I.S. Santos et al. 485 (UFG); idem, próximo ao Morro do Japonês, do lado direito da pista, sentido Cavalcante, GO-118, 24-VIII-2108, fl., fr., I.S. Santos et al. 510 (UFG); s.d. fl., M.J. Silva et al. 36 (UFG); idem, s.d. fl., M.J. Silva et al. 72 (UFG); idem, s.d. fl., fr., M.J. Silva et al. 7413 (UFG).

Segundo Dorr (2014), Epidendrum secundum é uma espécie Americana (Belize, Bolívia, Caribe, Colômbia, Costa Rica, Equador, El Salvador, Guatemala, Guiana, Honduras, México, Nicarágua, Panamá, Paraguai, Peru, Estados Unidos e Venezuela). No Brasil é encontrada em todas as regiões e latitudes, a exceção dos Estados do Piauí, Acre, Rondônia, Maranhão e Rio Grande do Norte, compreendendo os domínios fitogeográficos Amazônia, Caatinga, Cerrado e Floresta Atlântica (Barros et al. 2015, BFG 2018). No $\mathrm{PNCV}$, foi encontrada em campos e cerrados rupestres com rupícola, e em matas de galeria e em suas proximidades como epífita, com flores e frutos entre novembro e julho, apesar de ser encontrada com flores em outros períodos do ano, sobretudo, em meses mais chuvosos. Pode ser reconhecida pelo cauloma cilíndrico, não intumescido em pseudobulbo, folhas elípticas e oval-lanceoladas, inflorescência em corimbo com flores róseas, labelo 3-partido, lobos laterais e mediano com margem denticulada, calo amarelado, e cápsulas pendentes e glabras.

Relaciona-se morfologicamente com E. denticulatum Barb. Rodr., táxon que, apesar de não citado entre os aqui estudados, é confundido, pois cresce como terrícola ou rupícola em habitats semelhantes, apresenta o cauloma cilíndrico, folhas oval-lanceoladas e elípticas, coriáceas e flores róseas com labelo 3-lobado. Todavia, podem ser diferenciados pela morfologia floral, sobretudo, do labelo, onde E. secundum apresenta calo inteiriço (vs. formado por duas saliências ovoides e uma lamela em sua porção mediana, em E. denticulatum), irregularmente recortado (vs. não recortado) e amarelado (vs. branco).

Epidendrum secundum conforme Hágsater (1985) e Stancik et al. (2009), encontra-se inserido no Grupo Denticulatum, que reúne táxons com hábito cespitoso, dotados de inúmeras folhas coriáceas, pedúnculo longo e inflorescência com flores vistosas e polinário composto por caudículas granulosas. Segundo Pinheiro et al. (2009) e Rabelo (2016), esta espécie compreende um complexo específico denominado de Complexo E. secundum, o qual compreende, dentre outras: E. denticulatum Barb. Rodr., E. elongatum Jacq., E. ansiferum Rchb. f., E. versicolor Hoehne \& Schltr., e E. xanthinum Lindl.), espécies crípticas, polimórficas e com ampla plasticidade fenotípica (Brieger 1976-1977, Dunsterville 1979, Hágsater 1985, Pinheiro et al. 2009, Stancik et al. 2009, Rabelo 2016).

\section{Agradecimentos}

Ao Instituto Chico Mendes da Biodiversidade (ICMBio), pelo Projeto Levantamento Florístico do Parque Nacional da Chapada dos Veadeiros, Goiás, Brasil, financiado pelo CNPq (proc. no. 445669/2014-4), pela permissão de coletas no PNCV; ao CNPq, pela bolsas de Iniciação Científica concebida ao primeiro Autor e de Produtividade em Pesquisa ao segundo Autor; à Universidade Federal de Goiás, pela disponibilidade de transportes e instalações; aos Curadores dos Herbários mencionados ao longo do artigo; aos revisores por terem contribuído com a qualidade do manuscrito.

\section{Literatura citada}

Assis, F.N.M., Souza, B.C.Q., Medeiros-Neto, E., Pinheiro, F., Silva, A.E.B., \& Felix, L.P. 2013. Karyology of the genus Epidendrum (Orchidaceae: Laeliinae) with emphasis on subgenus Amphiglottium and chromosome number variability in Epidendrum secundum. Botanical Journal of the Linnean Society 172: 329-344.

Barros, F., Vinhos, F., Rodrigues, V.T., Barberena, F.F.V.A., Fraga, C.N., Pessoa, E.M. \& Forster, W. 2015. Orchidaceae. In: Forzza, R.C. et al. (coords.). Lista de Espécies da Flora do Brasil. Jardim Botânico do Rio de Janeiro, Rio de Janeiro. Disponível em http:// floradobrasil.jbrj.gov.br/jabot/floradobrasil/FB179 (acesso em 20-XII-2019).

BFG (The Brazil Flora Group). 2018. Brazilian Flora 2020: Innovation and collaboration to meet Target 1 of the Global Strategy for Plant Conservation (GSPC). Rodriguésia 69: 1513-1527.

Bosquetti, L.B. 2008. Análise da estrutura da paisagem e fitofisionomias do Parque Estadual dos Pireneus, Goiás, Brasil. Tese de Doutorado, Universidade de São Paulo, São Paulo. 
Brieger, F.G. 1976-1977. Gattungsreihe Epidendra. In: Brieger, F.G., Maatsch, R., Senghas, K. (eds.). Schlechter Die Orchideen, 3rd edn. Paul Parey, Berlin, pp. 509-549.

Carnevali, G. \& Romero, G.A. 1996. Orchidaceae Dunstervillorum VII: the Epidendrum nocturnum alliance in the Venezuelan Guayana and the Guianas. Lindleyana 11: 239-249.

Chase, M.W., Cameron, K.M., Freudenstein, J.V., Pridgeon, A.M., Salazar, G., van den Berg, C. \& Schuiteman, A. 2015. An updated classification of Orchidaceae. Botanical Journal of the Linnean Society 177: $151-174$.

Chaves, E. \& Soares-Silva, L.H. 2012. Floristic Survey of the Herbaceous-Shrub Layer of a Gallery Forest in Alto Paraíso de Goiás - Go, Brazil. Brazilian Archives of Biology and Technology 55: 715-724.

Cogniaux, A. 1898-1902. Epidendrum. In: Martius, C.F.P., Eichler, A.G., Urban, I. (eds). Flora brasiliensis. Munich, Oldenbourg, pp. 30-186.

Dardenne, M.A. \& Campos, J.E.G. 2002. Parque Nacional da Chapada dos Veadeiros, GO - Sítio de grande beleza cênica do Centro-Oeste brasileiro. In: Schobbenhaus, C., Campos, D.A., Queiroz, E.T., Winge, M., BerbertBorn, M.L.C. (eds.). Sítios Geológicos e Paleontológicos do Brasil. 1 ed. Brasília: DNPM/CPRM - Comissão Brasileira de Sítios Geológicos e Paleobiológicos (SIGEP), v. 1, pp. 323-333.

Dorr, L.J. 2014. Flora of Guaramacal (Venezuela): Monocotyledons. Smithsonian Contributions to Botany, 100.

Dunsterville, G.C.K. 1979. Orchids of Venezuela Epidendrum elongatum. American Orchid Society Bulletin 48: 447-454.

Eugênio, C.U.O., Munhoz, C.B.R. \& Felfili, J.M. 2011. Dinâmica temporal do estrato herbáceo-arbustivo de uma área de campo limpo úmido em Alto Paraíso de Goiás, Brasil. Acta Botanica Brasilica 25: 497-507.

Felfili, J.M., Rezende, A.V. \& Silva Júnior, M.C. (orgs.). 2007. Biogeografia do Bioma Cerrado: vegetação e solos da Chapada dos Veadeiros. Editora Universidade de Brasília/Finatec, Brasília.

Fernández-Concha, G.C. \& Ramírez-Morillo, I.M. 2003. Nomenclatural Novelties in the Orchidaceae from Venezuela and Guyana. Novon 13: 405-418.

Ferreira, M.E., Ferreira, L.G. \& Ferreira, N.C. 2006. Cobertura vegetal remanescente em Goiás: distribuição, viabilidade econômica e monitoramento. In: FerreiraJunior, L.G. (org.). Conservação da biodiversidade e sustentabilidade ambiental em Goiás: prioridades, estratégias e perspectivas. Goiânia, Goiás. pp. 148-164.

Fiedler, N.C., Merlo, D.A. \& Medeiros, M.B. 2006. Ocorrência de Incêndios florestais no Parque Nacional da Chapada dos Veadeiros, Goiás. Ciência Florestal 16: 53-161.
Flora do Brasil 2020 [em construção]. Epidendrum L. (Orchidaceae). 2020. Jardim Botânico do Rio de Janeiro. Disponível em http://floradobrasil.jbrj.gov.br/reflora/ floradobrasil/FB11518 (acesso em 14-III-2020).

Govaerts, R., Dransfield, J., Zona, S., Hodel, D.R. \& Henderson, A. 2020. World Checklist of Orchidaceae. Facilitated by the Royal Botanic Gardens, Kew. Disponível em http://wcsp.science.kew.org/ (acesso em 14-III-2020).

Hágsater, E. 1985. Towards an understanding of the genus Epidendrum. In: Tan, K.W. (ed.). Proceedings of the eleventh World Orchid Conference. Miami, pp. 195-201.

Hágsater, E. \& Salazar, G.A. 1993. Icones Orchidacearum, Fascicle 2: The genus Epidendrum, Part 1. A century of new species in Epidendrum. Asociación Mexicana de Orquideología, México. Disponível em https:// herbarioamo.org/index_archivos/Fascicle2.pdf (acesso em 26-XII-2019).

Hágsater, E. \& Saldaña, L.S. 2006. Icones Orchidacearum, Fascicle 8: The genus Epidendrum, Part 5. Species new and old in Epidendrum. Instituto Chinoin, Mexico. Disponível em https://herbarioamo.org/index_archivos/ Fascicle8.pdf (acesso em 26-XII-2019).

Hágsater, E. \& Sánchez, L. 2010. Icones Orchidacearum, Fascicle 13: The genus Epidendrum, Part 9. Species new \& old in Epidendrum. Instituto Chinoin, México. Disponível em https://herbarioamo.org/index_archivos/ Fascicle13.pdf (acesso em 18-VI-2020).

Hágsater, E. \& Sánchez, L. 2015. Icones Orchidacearum, Fascicle 15(1): The genus Epidendrum, Part 11. Species new \& old in Epidendrum. Instituto Chinoin, México. Disponível em https://herbarioamo.org/index_archivos/ Fascicle15(1).pdf (acesso em 19-VI-2020).

Hágsater, E. \& Santiago, E. 2018. Icones Orchidacearum, Fascicle 16(1): The genus Epidendrum, Part 12. Species new \& old in Epidendrum. Instituto Chinoin, México. Disponível em https://herbarioamo.org/index_archivos/ Fascicle16(1).pdf (acesso em 19-VI-2020).

Hágsater, E. \& Santiago, E. 2020. Icones Orchidacearum, Fascicle 17(2): The genus Epidendrum, Part 13. Species new \& old in Epidendrum. Instituto Chinoin, México. Disponível em https://herbarioamo.org/index_archivos/ Fascicle17_2.pdf (acesso em 19-VI-2020).

Hágsater, E., Santiago, E. \& Rodríguez-Martínez, L. 2016. Epidendrum lasiostachyum (Orchidaceae): A new Colombian species of the Epidendrum macrostachyum Group. Lankesteriana 16: 27-37.

Hágsater, E. \& Soto, M. 2003. Orchids of Mexico, Part 2 and 3. Icones Orchidacearum 5 and 6. Instituto Chinoin, A.C., Mexico City.

Hágsater, E. \& Soto-Arenas, M.A. 2005. Epidendrum. In: Pridgeon, A.M., Cribb, P.J., Chase, M.W. \& Rasmussen, F.N. (eds.). Genera Orchidacearum: 4. Epidendroideae (part one). Oxford University Press, Oxford, pp. 236-251. 
Hall, C.F., Klein, V.L.G. \& Barros, F. 2013. Orchidaceae no município de Caldas Novas, Goiás, Brasil. Rodriguésia 64: 685-704.

ICMBio - Instituto Chico Mendes de Conservação da Biodiversidade. 2009. Plano de Manejo do Parque Nacional da Chapada dos Veadeiros. Brasília.

Idárraga-Piedrahita, A., Ortiz, R.D.C., Callejas-Posada, R. \& Merello, M. 2011. Listado de las plantas vasculares del departamento de Antioquia. Flora de Antioquia 2: 9-939.

Jørgensen, P.M. \& Ulloa, U.C. 1994. Seed plants of the high Andes of Ecuador - A checklist AAU Rep.

Klein, V.P., Pessoa, E.M., Demarchi, L.O., Sader, M. \& Piedade, M.T.F. 2019. Encyclia, Epidendrum, or Prosthechea? Clarifying the phylogenetic position of a rare Amazonian orchid (Laeliinae-EpidendroideaeOrchidaceae). Systematic Botany 44: 297-309.

Kolanowska, M. \& Mystkowska, K. 2014. A new species of Epidendrum (Orchidaceae) from Panama. Polish Botanical Journal 59: 181-183.

Lima, J.H. 2014. Diversidade e riqueza de orquídeas epífitas em Matas de galeria da Floresta Nacional de BrasíliaDF. Dissertação de Mestrado, Universidade de Brasília, Brasília.

Lindley, J. 1852-1859. Epidendrum. In: Lindley, J. (ed.) Folia Orchidacea. J. Matthews (London), pp. 1-97.

Mantovani, J.E. \& Pereira, A. 1999. Ações Prioritárias para a Conservação da Biodiversidade do Cerrado e Pantanal. Brasília: INPE/Ministerio do Meio Ambiente/Funatura/ Conservation International/ Fundação Biodiversitas/ Universidade de Brasília. Brasília.

Marques, I., Draper, D. Riofrío, L., \& Naranjo, C. 2014. Multiple hybridization events, polyploidy and low postmating isolation entangle the evolution of neotropical species of Epidendrum (Orchidaceae). BMC Evolutionary Biology 14: 20-34.

Mendonça, R.C., Filgueiras, T.S. \& Fagg, C.W. 2007. Análise florística da Chapada dos Veadeiros. In: Felfili, J.M., Rezende, A.V., Silva Júnior, M.C. (orgs.). Biogeografia do Bioma Cerrado: vegetação e solos da Chapada dos Veadeiros. Editora Universidade de Brasília/Finatec, Brasília. pp. 121-192.

Mendoza, C.G., Matthias, J., Hágsater, E., Magallón, S., van den Berg, C., Lemmon, E.M., Lemmon, A.R., Salazar, G.A. \& Wanke, S. 2020. Target nuclear and off-target plastid hybrid enrichment data inform a range of evolutionary depths in the orchid genus Epidendrum. Frontiers in Plant Science 10: 1761.

MMA - Ministério do Meio Ambiente 2005. Cerrado: ecologia, biodiversidade e conservação. In: S., A., S.-S., J.C. \& F., J.M. (orgs). Ministério do Meio Ambiente, Brasília.
Moraes, A.P., Chinaglia, M., Palma-Silva, C. \& Pinheiro, F. 2013. Interploidy hybridization in sympatric zones: the formation of Epidendrum fulgens $\times$ puniceoluteum hybrids (Epidendroideae, Orchidaceae). Ecology and evolution 3: 3824-3837.

Mori, S.A., Silva, L.A., Lisboa, G. \& Coradin, L. 1989. Manual de Manejo do Herbário Fanerogâmico. 2 ed. CEPLAC, Ilhéus, Bahia.

Munhoz, C.B.R. \& Proença, C.E.B. 1998. Composição florística do município de Alto Paraíso de Goiás na Chapada dos Veadeiros. Boletim do Herbário Ezechias Paulo Heringer 3: 102-150.

Munhoz, C.B.R. \& Felfili, J.M. 2006. Floristics of the herbaceous and subshrub layer of a moist grassland in the Cerrado Biosphere Reserve (Alto Paraíso de Goiás), Brazil. Edinburgh Journal of Botany 63: 343-354.

Pabst, G.F.J. \& Dungs, F. 1975. Orchidaceae Brasilienses. I. Brucke-Verlag Schmersow, Hildesheim.

Pessoa, E.M. 2020. Epidendrum L. (Orchidaceae). In: Flora do Brasil 2020 [em construção]. Jardim Botânico do Rio de Janeiro. Disponível em http://floradobrasil.jbrj.gov.br/ reflora/floradobrasil/FB11518 (acesso em 18-III-2020).

Pinheiro, F., Koehler, S., Corrêa, A.M., Salatino, M.L.F., Salatino, A. \& Barros, F. 2009. Phylogenetic relationships and infrageneric classification of Epidendrum subgenus Amphiglottium (Laellinae, Orchidaceae). Plant Systematics and Evolution 283:165177.

Pinheiro, F. \& Cozzolino, S. 2013. Epidendrum (Orchidaceae) as a model system for ecological and evolutionary studies in the Neotropics. Taxon 62: 77-88.

Rabelo, P.M. 2016. "Complexo Epidendrum secundum" como modelo de estudo multidisciplinar na delimitação de espécies. Dissertação de Mestrado, Universidade Estadual Paulista, São Paulo.

Stancik, J.F., Goldenberg, R. \& Barros, F. 2009. O gênero Epidendrum L. (Orchidaceae) no Estado do Paraná, Brasil. Acta Botanica Brasilica 23: 864-880.

Thiers, B. 2020. Index Herbariorum. Part I: The herbaria of the world. New York Botanical Garden. Disponível em http://sweetgum.nybg.org/science/ih/ (acesso em 16-III-2020).

UNESCO. 2001. Cerrado Protected Areas: Chapada dos Veadeiros and Emas National Parks. Disponível em http://www.unesco.org/whc/sites/1035.htm (acesso em 16-III-2020).

Zanatta, M.R.V. 2012. Plantas raras e ameaçadas do Distrito Federal, Brasil. Dissertação de Mestrado, Universidade de Brasília, Brasília. 